\title{
Enhancement of Imperfection Detection Capabilities in TIG Welding of the Infrared Monitoring System
}

\author{
Jacek Górka ${ }^{1}$ (D) and Wojciech Jamrozik ${ }^{2, *(\mathbb{D})}$ \\ 1 Department of Welding Engineering, Silesian University of Technology, Konarskiego Str. 18a, \\ 44-100 Gliwice, Poland; jacek.gorka@polsl.pl \\ 2 Department of Fundamentals of Machinery Design, Silesian University of Technology, Konarskiego Str. 18a, \\ 44-100 Gliwice, Poland \\ * Correspondence: wojciech.jamrozik@polsl.pl
}

check for updates

Citation: Górka, J.; Jamrozik, W. Enhancement of Imperfection Detection Capabilities in TIG Welding of the Infrared Monitoring System. Metals 2021, 11, 1624. https:/ / doi.org/10.3390/met11101624

Academic Editor:

Alberto Campagnolo

Received: 14 September 2021

Accepted: 4 October 2021

Published: 13 October 2021

Publisher's Note: MDPI stays neutral with regard to jurisdictional claims in published maps and institutional affiliations.

Copyright: (c) 2021 by the authors. Licensee MDPI, Basel, Switzerland. This article is an open access article distributed under the terms and conditions of the Creative Commons Attribution (CC BY) license (https:// creativecommons.org/licenses/by/ $4.0 /)$.

\begin{abstract}
For a low cost, there are industrial infrared monitoring systems used for imperfection detection and identification in welded joints. The key drawback that impedes real life industrial applications is the low spatial resolution, as well as the temporal resolution of low-cost infrared (IR) cameras. This is also the case in tungsten inert gas (TIG) welding. Taking into consideration the influence of voltage on the arc energy and heat input, high frequency sampled voltage was used to evaluate the interpolated temporal resolution of IR sequences. Additionally, a reflected temperature correction method was proposed to reduce the uncertainty of absolute temperature measurement with a thermographic camera. The proposed method was applied to detect several imperfection types, such as lack of or incomplete penetration as well as incorrect weld shape and size (including burnouts). Results obtained for different interpolation factors were compared. The obtained results emphasize the validity of reflected temperature correction method. For the weld defects detection task, the smallest detectable defect was found for various interpolation factors. Moreover, the correspondence of arc voltage and the joint temperature was checked. Additionally, a set of decision rules was elaborated on and applied to distinguish between various joint conditions. It was found that defects that do not have symmetrical temperature distribution with respect to the joint axis are harder to identify.
\end{abstract}

Keywords: TIG welding; Inconel superalloys; thermography; emissivity; reflected temperature; temporal interpolation

\section{Introduction}

Welding technology over past years has been employed in a wide variety of industries such as automobile, shipbuilding, aerospace, oil and gas, and many others. Research on welding technology, devices, as well as regarding quality assurance in welding, including simulation and nondestructive testing (NDT) methods, have become more imminent while the manufacturing industry develops rapidly [1-8]. Welding quality is affected by many factors, including but not limited to process parameters, welding speed, arc voltage, welding current, shielding gas, welding device quality, welder skill in manual welding, and workpieces preparation quality $[9,10]$. As the welding process is dynamic and complex, it is vulnerable to a wide range of instabilities that can lead to product defects or equipment failure. According to this, there is a vital need for early detection of defects and to control the welding process to ensure the welding quality. In order to obtain the ideal weldment, inspection technology has been widely used in the pre-process, in-process, and post-process stages of welding. The pre-process involves seam tracking, clamping, gap, and part geometry [11], wherein primary methods are machine and ultrasonic vision. The post-process mainly manages the weld forming quality mostly using non-destructive testing, magneto-optical imaging, X-ray transmission [12], metallographic inspection techniques, optical microscope (OM), scanning electron microscope (SEM), and ultra-depth 
three-dimensional microscope [13]. The in-process focuses on monitoring welding stability. Welding technology involves not only the interaction between the weldment materials and the heat source but also various kinds of signals in the welding process. Optical signal, acoustics signal, thermal signal, and current signal could be generally detected through the corresponding sensors [14], and the multi-sensors are also often fused to improve the performance of monitoring [15]. In addition to ordinary monitoring sensors, some special techniques may also be employed, such as inline coherent imaging [16] or the X-ray diffraction machine [17]. One in-process monitoring method that is often studied, developed, and applied in research is based on contactless temperature measurements made by optical pyrometers, near infrared cameras, LWIR cameras (thermographic cameras), and MWIR cameras. Applying thermography (IR imagining) for monitoring and diagnosing welding and welded joints quality is an engineering and scientific task that has been explored for more than sixty years [18-25]. Nevertheless, even in most recent publications there are still several issues unsolved that prevents the implementation of those methods in the industrial environment. Firstly, it is connected with limitations of IR imagining devices. There is a strong dependence between IR camera costs and performance, but even for expensive devices, some parameters still remain insufficient, e.g., spatial resolution of IR cameras are relatively low in comparison to visible light cameras, thus the detection of small areas that can be anomalies in temperature distribution is difficult. Secondly, there is a group of problems connected to the way the temperature is measured by thermographic cameras. The measurement is an indirect one and several factors must be set to calculate temperature from the infrared radiation emitted by an object. Additionally, the welding process demands a large amount of heat that is needed to melt the edges of material pieces to produce the joint. In the tungsten inert gas (TIG) welding, the torch introduces high thermal noise to the measurement setup. Metal surfaces (including surfaces of non-ferrous alloys and superalloys) have a small absorptivity and thus a weak emissivity in the infrared images, totaling to about $5 \%$ of the black-body emissivity. The radiance emitted by metallic surfaces is weak. Consequently, obtained infrared images are blurry and faint. Additionally, there is a possibility of grease patches or oxidized zones and spatter that have different (higher) emissivity levels than the base material surface. Those areas are often interpreted as hot spots that are regarded to be damaged zones. Moreover, high reflectivity of the metallic surface causes the phenomena of parasitic reflection. In the case of welding, the heat from the hot torch, electrode, and welding arc is reflected by the surface that acts as a mirror in the infrared spectrum. Reflected hot areas mask the real temperature on the material surface and complicate the interpretation of acquired thermograms. Some experts attempt to weaken the interference by using the shield plate or filter [26]. However, the interference cannot be avoided thoroughly. As the vast majority of new metallic materials, alloys, and superalloys are used for harsh environments, are characterized by a low thermal expansion coefficients, have relatively good weldability (cobalt, titanium, and nickel), and have low emissivity in the wavelength band used mostly by LWIR cameras $(8-14 \mu \mathrm{m})$, there is a constant demand for novel acquisition and processing methods that will limit these drawbacks. In the TIG welding, a constant current mode is used. Current affects the melt-off rate or consumption rate of the electrode concerning whether it be a stick electrode or wire electrode. The higher the current level, the faster the electrode melts; the lower the current, the lower the electrode's melt-off rate. Additionally, for higher current, the weld penetration increases and as welding current decreases, weld penetration decreases. Voltage controls the length of the welding arc, resulting in the width and volume of the arc cone. As voltage increases, the arc length becomes longer (and the arc cone becomes broader) and as it decreases, the arc length becomes shorter (and the arc cone becomes narrower). There is also a relationship between the arc length and the distribution of the heat transferred to the welded material. For shorter arc lengths, the voltage is decreased and, as a consequence, less heat is transferred to a larger area on the material surface, thus the bead width is narrower and the penetration depth can decrease only slightly. Considering the relationship between current and arc voltage for constant current mode, a 
change of the welding current (and amount of heat transferred into the joint) will cause a change in the level of the arc voltage.

In the present paper, a research study concerning the possibility of using an IR camera with a low acquisition rate to assess the condition of the welding process and the quality of welded joints is presented. It was assumed that diagnostic signals extracted from thermogram sequences can be enriched by temporal interpolation of input data. This procedure could benefit in the obtainment of more informative signals, which, after evaluation, allows for faster and more robust detection and identification of possible defects. Moreover, an innovative reflected temperature mapping method was introduced to have measured temperature distributions be less affected by disturbances introduced by the heat emitted by the welding torch and welding arc. The proposed correction method cannot be regarded as a method for the calculation of exact temperature values in all specific regions of joint formation. Rather, it is a method that can be applied to increase the confidence of relative temperature data and to establish the relative relations between temperatures in certain joint parts closer to real ones. Additionally, it can be used to assess process dynamics in terms of heating and cooling dynamics, or regarding $\mathrm{t}_{8 / 5}$ curve estimation. To assess how long acquisition delay maintains the demanded diagnostic signal dynamic, a correlation between the temperature features and welding arc voltage was performed.

\section{Materials}

The tests were carried out on the joints of thin sheets with a thickness of $1 \mathrm{~mm}$ of nickel superalloys-type Inconel 600, welded by the TIG method. The sheets used to make the welds were from the industrial process of Huntington Alloys Corporation (Huntington, WV, USA), involving the smelting of Inconel 600 superalloy ingots in an electric furnace. Next, a plastic processing by cold rolling with intermediate heat treatment (recrystallization annealing) was performed. The chemical composition of the tested sheets is shown in Table 1. The Casto TIG 2002 device (Castolin GmbH, Kriftel, Germany) was used for welding sheets from the investigated Inconel nickel superalloys, as depicted in Figure 1. The TIG welding of sheets was carried out in laboratory conditions with the following constant parameters: shielding gas of $\mathrm{Ar} 12 \mathrm{~L} / \mathrm{min}$, ridge shielding gas of $\mathrm{Ar} 3 \mathrm{~L} / \mathrm{min}$, tungsten electrode (thoriated), and WT20 with a diameter of $2.4 \mathrm{~mm}$. The arc voltage was measured using a NI USB-6009 (NI, Austin, TX, USA) card with an acquisition rate of $25 \mathrm{kHz}$. Before feeding the measuring transducer, the voltage was conditioned using the LEM LV 25 P voltage transducer (LEM International SA, Plan-les-Ouates, Switzerland) with a voltage range of $0-10 \mathrm{~V}$ that was suitable for the acquiring task. K-type thermocouples ( $\mathrm{Ni}-\mathrm{NiCr}$ wire with a diameter of $0.2 \mathrm{~mm}$ ) were used to measure welding thermal cycles. According to the PN-EN 60584-1:2014-04 standard, these thermocouples were characterized by an accuracy of $\pm 0075 \times \mathrm{T}$ in the temperature range from -0 to $+200{ }^{\circ} \mathrm{C}$. They were connected to the Agilent 34970A digital recorder (Agilent Technologies Inc. Santa Clara, CA, USA). To the surfaces of the test specimens, thermocouples were attached using the Labfacility L60+ (Labfacility Limited, Bognor Regis, England) dedicated for thermocouple welding. The sampling rate of the temperature measurement was $5 \mathrm{~Hz}$. Measurement of the temperature distribution on the welded joints' surface was conducted with the FLIR A655sc infrared camera (IR CAM, spectral range of 7.5-14.0 $\mu \mathrm{m}$ ) with a $25 \mathrm{~mm}$ lens (Teledyne FLIR LLC, Wilsonville, OR, USA) Figure 1. The spatial resolution of the camera was $640 \times 480 \mathrm{px}$ and the temporal resolution as well as the acquisition frequency was $60 \mathrm{~Hz}$ (60 fps). For the IR camera, a dedicated software, namely FLIR ResearchIRx64, was used. The acquisition software for voltage measurements was written in NI LabVIEW 2017. The PC used as the system central unit was equipped with: Intel Core i7-7700K, 4.2 GHz, ASUS TUF Z270 MARK 2 motherboard, and Corsair Vengeance LPX 16 GB DDR4 $3000 \mathrm{MHz}$ RAM. Data post-processing and analysis was performed in the MATLAB R2021a environment with the use of an additional Teledyne FLIR Science File SDK (to read and process IR sequences). The radiograms were made on the X-ray YXLON SMART EVO 
225DS device with a focal spot size of $1.0 \mathrm{~mm}$ (YXLON Copenhagen, Denmark), equipped with the NOVO-15W detector with a pixel size of $148 \mu \mathrm{m}$.

Table 1. Chemical composition of the investigated inconel superalloy.

\begin{tabular}{cccccccccccccccc}
\hline \multirow{2}{*}{$\begin{array}{c}\text { Super- } \\
\text { Alloy }\end{array}$} & $\mathbf{1 0}$ & $\mathbf{N i}$ & $\mathbf{C r}$ & $\mathbf{F e}$ & $\mathbf{M o}$ & $\mathbf{N b}$ & $\mathbf{C o}$ & $\mathbf{M n}$ & $\mathbf{C u}$ & $\mathbf{A l}$ & $\mathbf{T i}$ & $\mathbf{S i}$ & $\mathbf{C}$ & $\mathbf{S}$ & $\mathbf{P}$ \\
\hline $\begin{array}{c}\text { Inconel } \\
600^{*}\end{array}$ & 74.43 & 15.76 & 8.60 & - & 0.08 & 0.05 & 0.25 & 0.09 & 0.18 & 0.27 & 0.12 & 0.01 & 0.002 & 0.005 \\
\hline
\end{tabular}

${ }^{*} \mathrm{Nb}+\mathrm{Ta}-0.08 \% ; \mathrm{Ni}+\mathrm{Co}-74.48 \% ; \mathrm{Ta}-0.0002 \%$

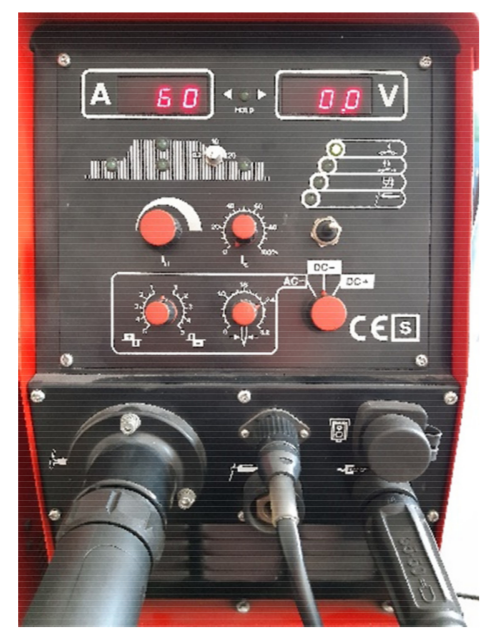

(a)

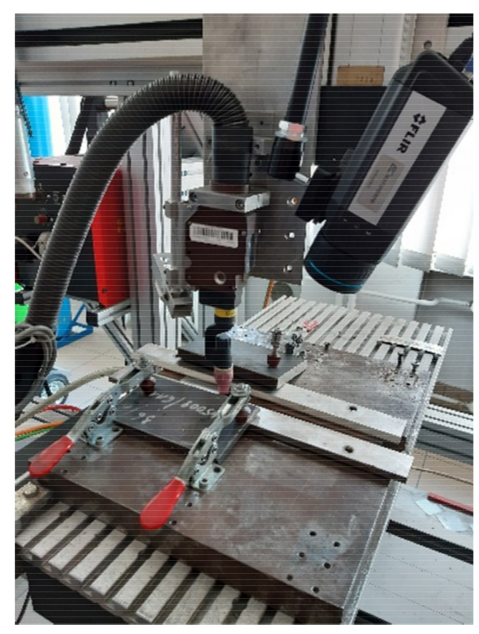

(b)

Figure 1. The welding device (a) and tungsten inert gas (TIG) torch (b) used during the studies.

\section{Methods}

\subsection{Emissivity and Reflected Temperature Correction}

Based on the literature review and on previous research [9], the initial emissivity of the Inconel surface was set to $\varepsilon=0.2$. It was estimated in an examination of Inconel 600 samples in an oven, where the temperature of the samples was increased to $600{ }^{\circ} \mathrm{C}$. During this test, the hysteresis of the temperature in the oven and the thermal capacity of the sample were not considered. Additionally, there was no cover that protected measured sample-form environmental noise, which could lead to the appearance of hotspots and other increased temperature areas that can influence the quality of the emissivity estimation. During the next iteration of studies on IR measurement methodology that can be easily applied for monitoring as well as for the condition and/or quality assessment of welded joins/the welding process, thermocouples were used to measure the real temperature that appeared on the sample surface. Moreover, when handling a material of such low emissivity that is highly vulnerable to reflections generated by various heat sources, the determination of the reflected temperature is a vital task. In a TIG welding process, the only heat source that can affect the thermographic measurements is a hot welding torch and welding arc. To obtain reference temperature values for trials, a set of thermocouples (type K) was bounded to the one workpiece (Figure 2). Thermocouples were spaced $20 \mathrm{~mm}$ apart from each other, while the offset from the workpiece edge was $10 \mathrm{~mm}$. Depending on the configuration, the offset from the joint was $3 \mathrm{~mm}$ or $6 \mathrm{~mm}$. Thermocouples were covered with a thin layer of water glass to prevent the measuring tip from experiencing damage that can be caused by too-high temperatures. 


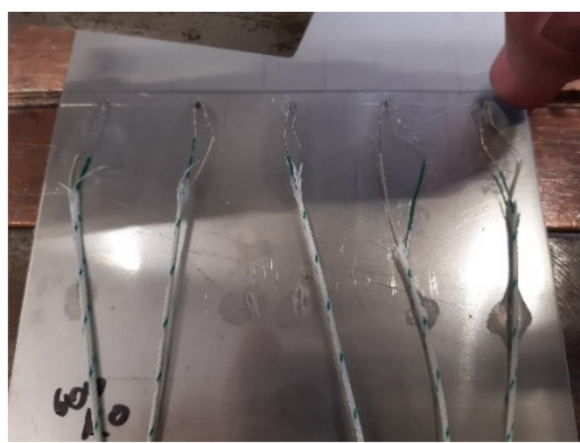

(a)

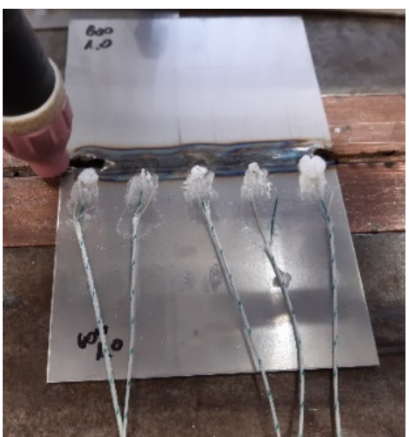

(b)

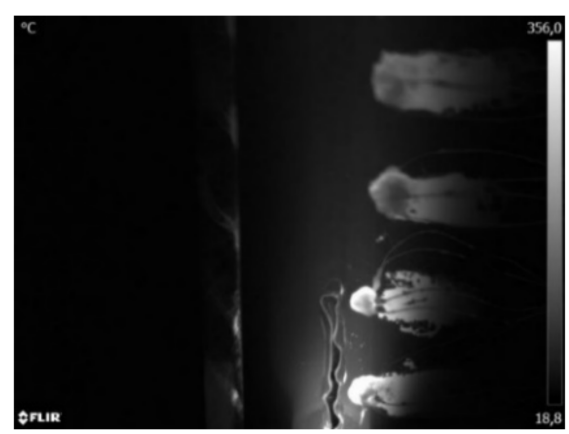

(c)

Figure 2. Thermocouples installed on test sample (a) before welding and (b) after welding, and (c) an IR image of hotcovered thermocouples.

The reflected temperature correction map was generated as a result of a procedure presented in Figure 3. We next discuss our first assumption concerning the possible range of metallic surface emissivity. Based on the commonly available emissivity tables and on previous research, the emissivity range was set at $\hat{\varepsilon} \in 0.1 ; 0.3$. The range of possible reflected temperature $T_{R}$ was also narrowed down $T_{R} \in 50 ; 1000{ }^{\circ} \mathrm{C}$. Then, according to a greedy/exhaustive optimization algorithm, a parameter set consisting of the emissivity value and ten values of the reflected temperature were found. For the search procedure, the temperature step was set to $\Delta=5^{\circ} \mathrm{C}$, while the emissivity increase was $\Delta=0.01$. For all combinations of those parameters, the temperature on the surface of the welded sample that was measured using the IR camera was recalculated. Then, the mean-squared error (MSE) between the temperature measured by the thermocouples and the mean temperature red on a thermogram in a neighborhood of $3 \times 3$ pixels located as near as possible to the thermocouple (in a region that was not affected by the water glass cover) was calculated. It was demanded because there was no possibility to obtain corrected temperatures directly at the point where the thermocouple was placed, thus an approximate way was applied. Due to the water glass coverage, the area of each thermocouple was contaminated by the spot of the material, which had very different radiational properties than the metallic base material (Inconel 600). Temperature on the IR image was calculated as an average of the temperature that had the same column index as the TC tip. For samples S25 and $\mathrm{S} 27, \mathrm{TC}$ was placed with an offset of $3 \mathrm{~mm}$ from the joint ax. For samples S26 and S28, the offset was $6 \mathrm{~mm}$. The parameters of welding for those samples are gathered in Table 2 . The procedure was conducted for all images in sequences S25-S28. After analysis of the MSE error, the results of the optimization were values of pairs (emissivity and reflected temperate), consisting of ten element sets of reflected temperature values. The emissivity was a global setting, as was for the whole thermogram, while the reflected temperature was a set of temperature values located in the middle of the neighborhood that was used in the search procedure. To generate a map of reflected temperatures, a spatial cubic interpolation was used. Seed values for the interpolation process included temperatures obtained as a result of the previous search procedure.

Mounting TCs only on one side of the joint was dictated by the fact that in the case of welding workpieces made by the same material, the heat distribution should be symmetrical. According to that, we decided to mount TCs only on one side of the joint, calculate half of the reflected temperature correction map, and then after produced a mirror image to put both halves together. Nevertheless, applying other techniques, such as two-color pyrometry, would increase the quality of solution, allow us to gather temperature scans from the weld as well as from the zones located on both sides of the joint, and lead to a more reliable approach with higher a certainty of results. 


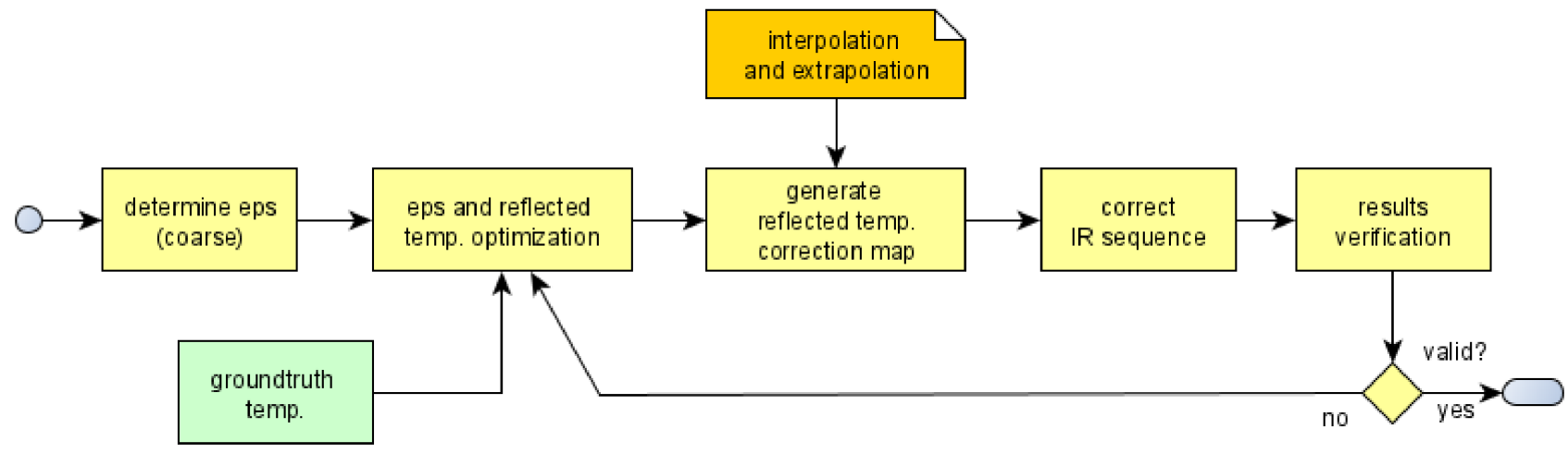

Figure 3. The reflected temperature correction map.

Table 2. Parameters of the welding processes selected for making sample joints.

\begin{tabular}{cccc}
\hline Scheme 25 & Current (A) & Welding Speed (mm/s) & Thermocouple Offset (mm) \\
\hline S25 & 50 & 5 & 3 \\
S26 & 50 & 5 & 6 \\
S27 & 50 & 4 & 3 \\
S28 & 50 & 4 & 6 \\
\hline
\end{tabular}

\subsection{Detection and Identification of Weld Defects Based on Interpolated IR Sequences}

The defect detection and identification diagram is presented in Figure 4. It is assumed that there are two processing paths. The main path is devoted to the processing of IR sequences. After applying the emissivity and reflected temperature corrections, a small ROI (Region Of Interest) was selected to reduce the computational load and to assure the correspondence between the spatial and temporal domains to allow for localization of possible defects. In the research study, two rectangular ROIs were chosen. Both were of size $100 \times 10 \mathrm{px}$ and the vertical symmetry axis of ROI coincided with the welding line. The first ROI (R1) covered an area near the welding torch (about $5 \mathrm{~mm}$ offset between ROI bottom and torch edge). The second ROI (R2) was translated from the R1 on $20 \mathrm{~mm}$, as depicted in Figure 5.

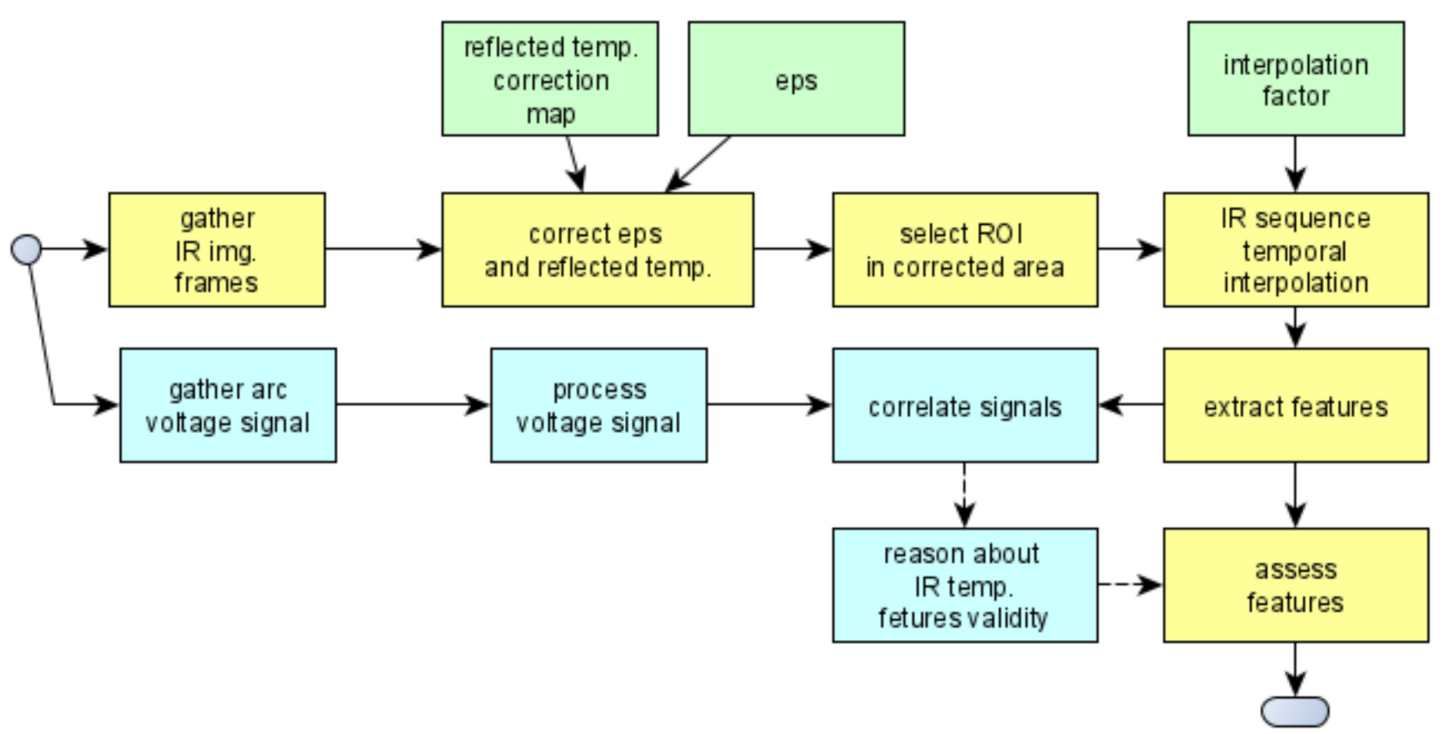

Figure 4. Detection of weld defects based on interpolated infrared (IR) sequences with the step of voltage = temperature distribution features correlation. 


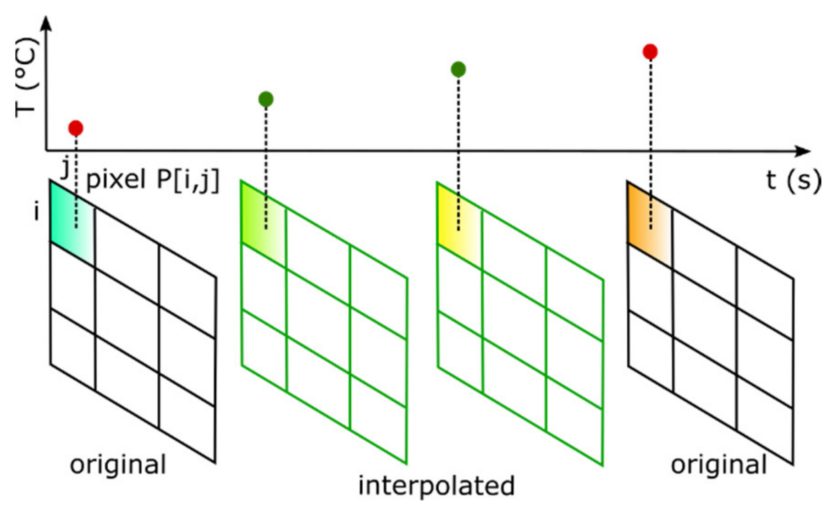

Figure 5. Concept of the temporal interpolation of the thermogram sequence.

The crucial task in the processing flow is the interpolation stage. For the research purpose, several interpolation factors were chosen: 2, 4, 12, 24, 48, 96, and 192. In the research study, the IR image acquisition frequency was $60 \mathrm{~Hz}$. The input sequence for the interpolation process required, as a result, a sequence of desired frequency, which was about: $30 \mathrm{~Hz}$, $15 \mathrm{~Hz}, 5 \mathrm{~Hz}, 2.5 \mathrm{~Hz}, 1.25 \mathrm{~Hz}, 0.625 \mathrm{~Hz}$, and $0.3 \mathrm{~Hz}$. Common interpolation methods were examined, namely nearest neighbor, linear, and cubic methods [27]. Obtained sequences were then assessed using several point features. Obtained diagnostic signals were than subjected to decision rules that determine the condition (quality) of the joint. The temporal interpolation of signals was introduced to simulate a situation, wherein the thermogram acquisition frequency was limited or the time needed for reflected temperature correction was too short, to perform it in a pixel-wise manner. The interpolation was performed as presented schematically in Figure 6. For a chosen interpolation factor, a specified number of new images (2D arrays) is generated. New images are generated as a set of $1 \mathrm{D}$ signals that are interpolated. Corresponding pixel-form input-set images are the given points for each 2D signal. The whole considered IR image has a spatial resolution of $640 \times 480 \mathrm{px}$, thus 307,200 signals have to be interpolated and then merged to generate the new sequence.

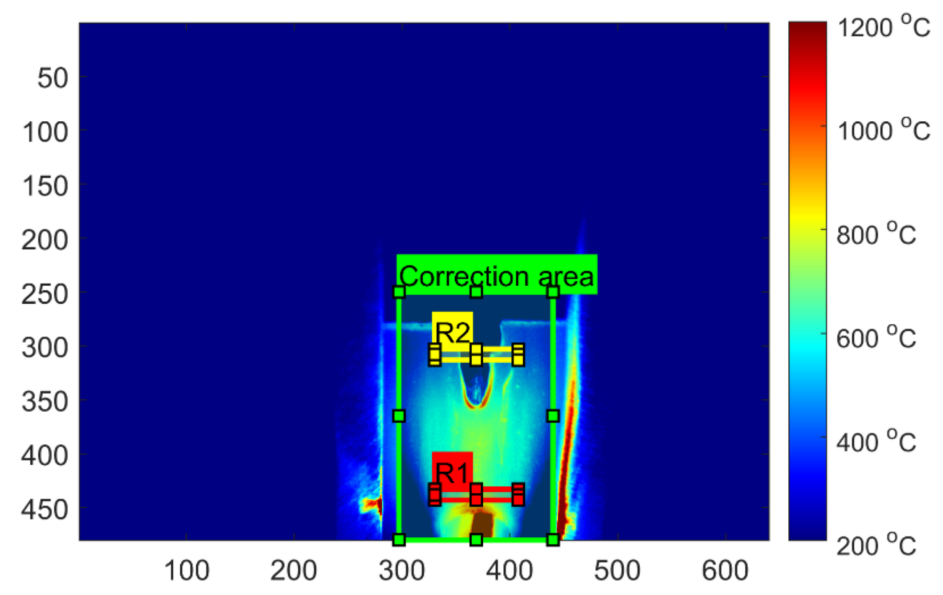

Figure 6. Localization of ROIs (Region of Interest) on an exemplary thermogram.

There weas also an intermediate stage introduced. It consisted of a correspondence estimation between temperature changes and the welding arc voltage change dynamics. The correlation between the envelope of the voltage signal and the mean temperature signal was calculated for the desired ROI over time. This correlation was used to determine if the diagnostic signals extracted from interpolated IR sequences were reflecting the phenomena connected with the heat generation that occurred during welding. The analysis of the relationship between voltage signal features and mean temperature that was calculated for a small ROI (R1) was used to check the detectability of instabilities that were present in 
the change of value of voltage signals or in certain dynamics of signals. First, to remove high frequency noise introduced by the measurement system, voltage signal was filtered using a lowpass filter with the cutoff frequency of $=1 \mathrm{kHz}$. Then, to transform the signal of still-relative high frequency to low frequency, an upper envelope was determined. The envelopes were determined using spline interpolation over local maxima separated by at least 200 samples. After this operation, the voltage envelope signal $\boldsymbol{U}_{y u, i}$, where $i$ is the identifier of the considered sample, was decimated in order to match the sampling rate with the temperature signal $T_{i, j}^{k, n}$, where $j$ is the ROI identifier, $k$ is the interpolation identifier $k \in\left\{N^{\prime},{ }^{\prime} L^{\prime}, C^{\prime}\right\}$, and $n$ is the interpolation factor. The $T_{i, j}^{k, n}$ signal is a mean temperature calculated for certain ROI over time. In other words, it is obtained by averaging 3D signal $T_{i, j}^{k, n}[H ; W ; M]$ by each ROI in both dimensions for all thermograms in the sequence for given sample, interpolation type, and factor. The range of the decimated voltage envelope signal ${ }^{d} \boldsymbol{U} y_{i}$ is then fitted to temperature range $\left({ }_{f}^{d} \boldsymbol{U} y_{i}\right)$, which is demanded to calculate the error signal, as it is the absolute normalized difference of the mean region temperature and the voltage envelope, expressed as follows:

$$
\operatorname{err}_{i, j}^{k, n}=\left|\operatorname{norm}\left(T_{i, j}^{k, n}-{ }_{f}^{d} u_{y u, i}\right)\right|
$$

The final error signal is obtained as the difference between adjacent elements of the err vector:

$$
\operatorname{Error}_{i, j}^{k, n}=\operatorname{err}_{i, j}^{k, n}[m]-\operatorname{err}_{i, j}^{k, n}[m-1] .
$$

To determine the condition and quality of the joint, a simple method was applied. It is based on the analysis of the temperature distribution that was extracted using a line profile that is perpendicular to the welding path. The profile was located on the bottom edge of the R1 ROI.

$$
\begin{aligned}
& \boldsymbol{T}_{b}^{m}[1 ; M]=\operatorname{mean}\left(\boldsymbol{T}_{i, j}^{k, n}\left[h_{x} ; \frac{w_{j}-b}{2}: \frac{w_{j}+b}{2} ; \mathrm{M}\right]\right) \\
& \boldsymbol{T}_{b}^{o}[1 ; M]=\operatorname{mean}\left(\boldsymbol{T}_{i, j}^{k, n}\left[h_{x} ; 1: \frac{b}{2}, w_{j}-\frac{b}{2}: w_{j} ; \mathrm{M}\right]\right)
\end{aligned}
$$

where $b$ is the number of pixels corresponding to the bandwidth, $b=w_{j} \cdot(b \% / 100), w_{j}$ is the width of the $j$-th ROI, and $b \%$ is the relative bandwidth.

\subsection{Welds Used for the Method Evaluation}

There were set of welds made with different parameters, as presented in Table 3 . Welding technology was chosen because it allows for the creation of correct joints and joints that are characterized with common defects that can occur in a real life industrial application.

Table 3. Parameters of welding processes selected for making the sample joints (511 indicates incomplete fill; 510 indicates burn-through; and 402 indicates a lack of penetration/incomplete penetration).

\begin{tabular}{ccccc}
\hline Sample ID & Current (A) & Welding Speed $(\mathbf{m m} / \mathbf{s})$ & Thermocouple Offset $(\mathbf{m m})$ & Defect \\
\hline S13 & 50 & 3 & - & \\
S14 & 50 & 3 & - & 510 \\
S15 & 50 & 4 & - & \\
S16 & 50 & 4 & - & \\
S17 & 50 & 5 & - & \\
S18 & 50 & 5 & - & 511 \\
S19 & 50 & 7 & - & 402 \\
S20 & 50 & 7 & - & 510 \\
S22 & 70 & 4 & - & 510 \\
S23 & $75 / 80$ & 4 & - & 510 \\
S24 & 70 & 4 &
\end{tabular}




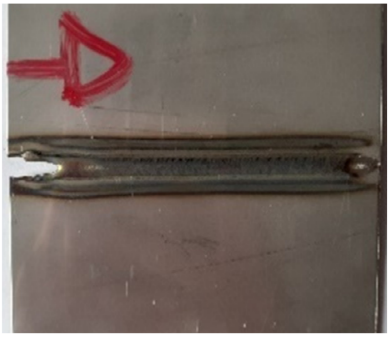

(a)

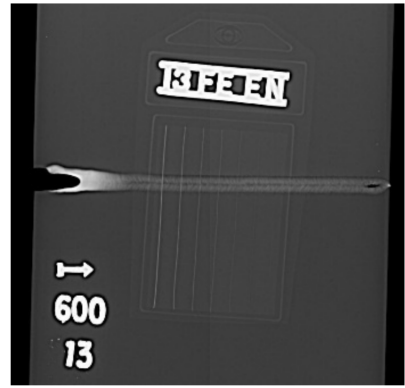

(e)

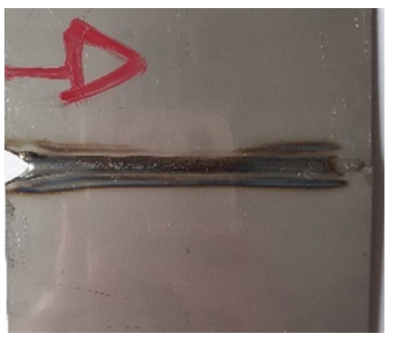

(b)

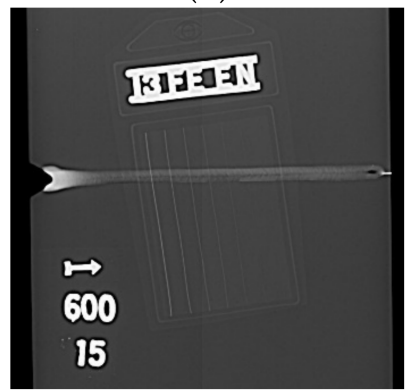

(f)

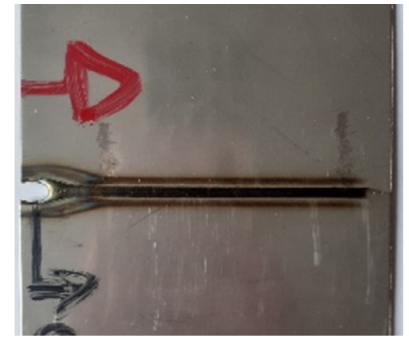

(c)

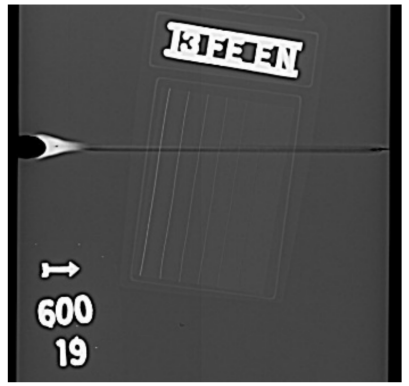

(g)

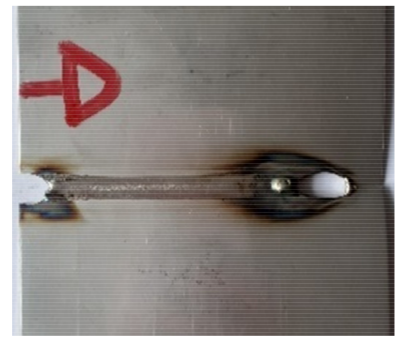

(d)

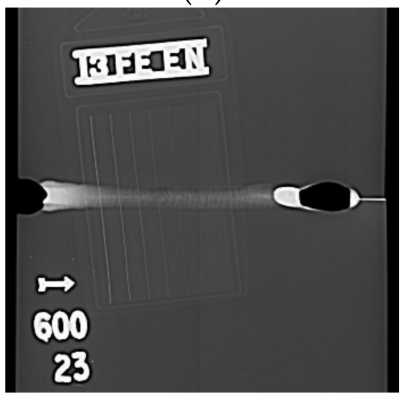

(h)

Figure 7. Selected welds and view of weld face: (a) sample S13, (b) sample S15, (c) sample S19, and (d) sample S23. Radiograms of the considered welds: (e) sample S13, (f) sample S15, (g) sample S19, and (h) sample S23.

The thermograms taken during the welding process were not processed in any way, as the bottom part the welding torch is visible in Figures $8 \mathrm{a}-\mathrm{c}$ and 9 . In Figure $8 \mathrm{~d}$, at the bottom part of the thermogram, a burn-through is visible, and the welding torch is cooler that in other thermograms presented. The view provided in Figure 8 is interesting as there is a compete burn-through over the entire workpiece length. In this case, the metal sheets were not joined at all. Apparently, hotter regions in the form of vertical lines visible in all thermogram are reflections caused by plates that were used to stabilize and secure welded sheets. Those plates, held by clamps, are visible in Figure $1 \mathrm{~b}$.

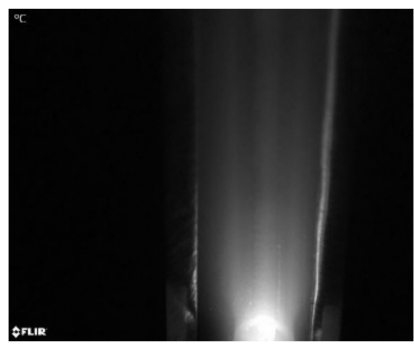

(a)

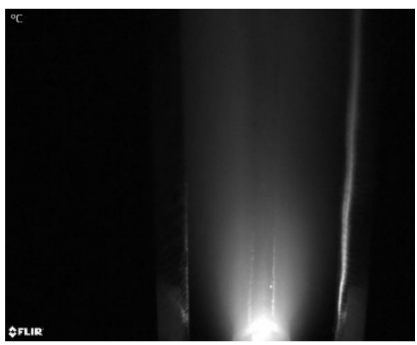

(b)

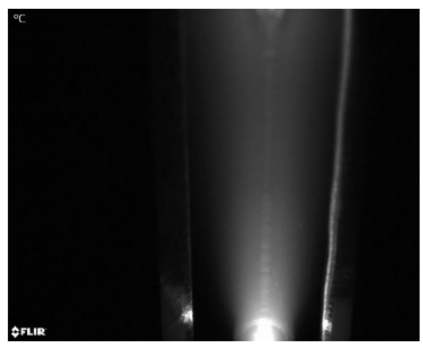

(c)

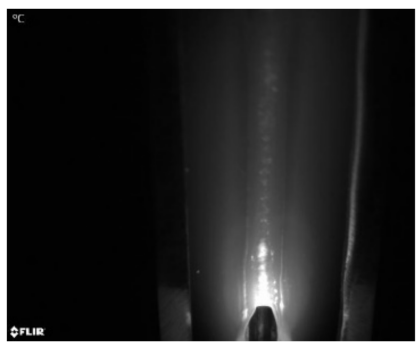

(d)

Figure 8. Sample IR images of weld face sides: (a) sample S13, (b) sample S15, (c) sample S19, and (d) sample S23. 


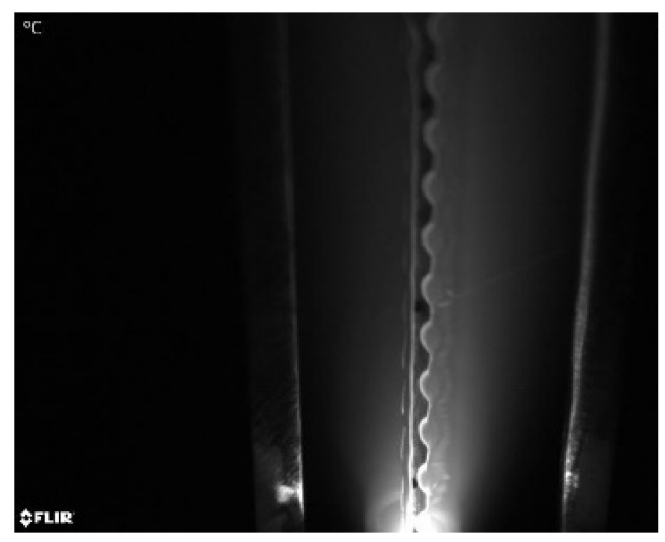

Figure 9. Sample IR image of weld face side from sample S24, where metal plates were not joined because of the too-large offset between them.

\section{Results and Discussion}

At the first stage of the thermograms' preprocessing, before the decision process, calculations of the reflected temperature correction map was made. Based on all the datasets gathered for the samples with mounted thermocouples, a greedy search was carried out to find the best combination of reflected temperature and emissivity. In applying the obtained emissivity value $=0.13$ and the correction map Figure 10, it was possible to derive a high quality and more accurate thermogram Figure 11. It can be seen that applying both the reflected temperature correction and the proper emissivity value leads to an enhanced image, in which more details and small temperature differences are visible. Especially in the area near the welding torch, the quality gain is high. Nevertheless, corrected temperature values are not exact because there was only one correction map applied, regardless of the process parameters. When there was a lower welding speed and higher welding current, the amount of heat generated by the welding arc and transferred to a welding pool in the time unit was higher, as in the case of lower current and higher welding speed. The momentary distribution of the reflected temperature at the workpiece surface also differed. In one case, it was higher, and in other cases, it was lower than in the considered correction map. Additionally, the shape of the correction field was not optimal and it was caused by the limited number of thermocouples mounted on the welded material, which determines the number of reference measurement points. After correction, the difference between the real temperature and the corrected temperature was lower as in the case of the uncorrected one. The error value was not constant, as it depended on the material surface characteristics, process parameters, equipment type, and shape.
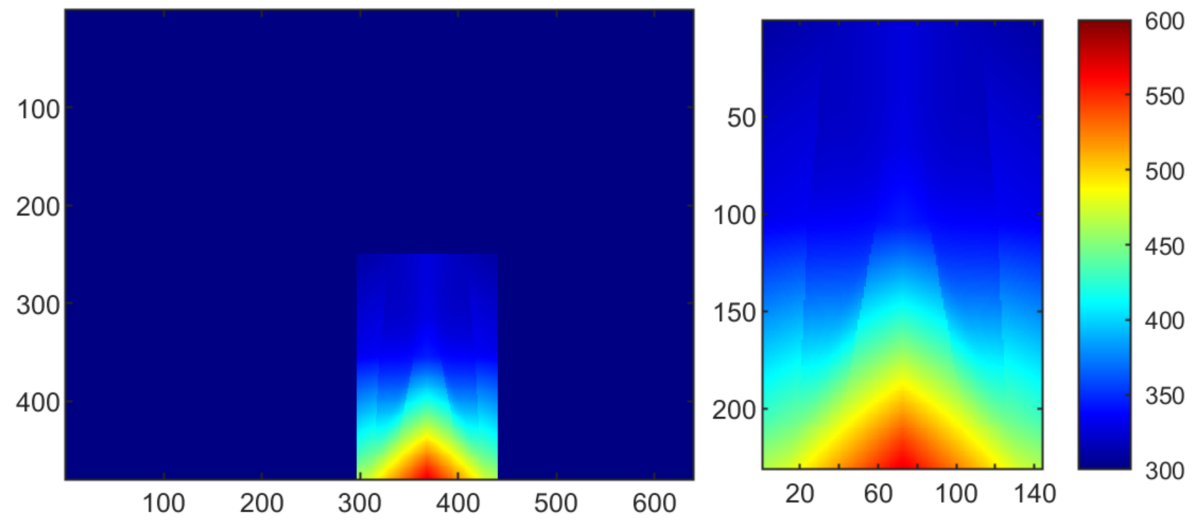

Figure 10. Estimated reflected temperature map. 
(a)

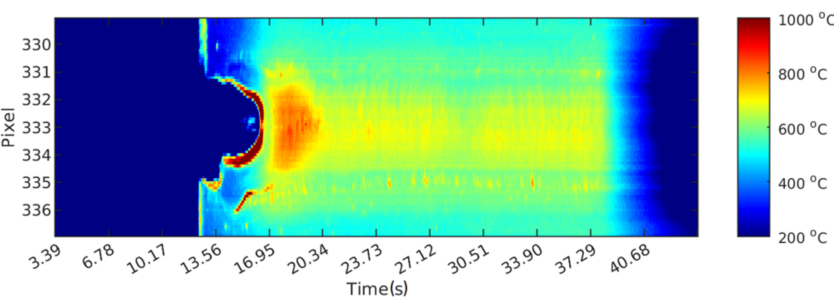

(b)

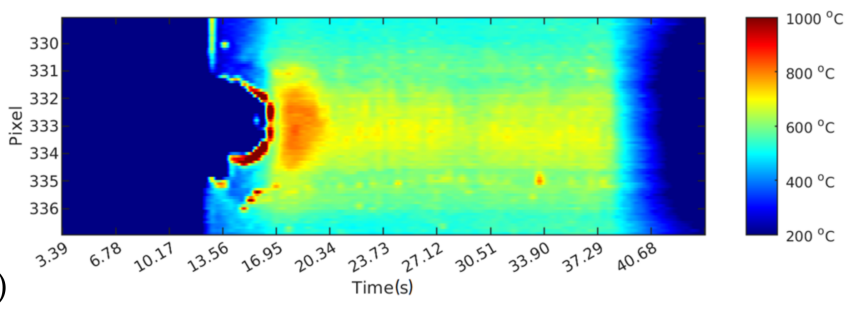

d)

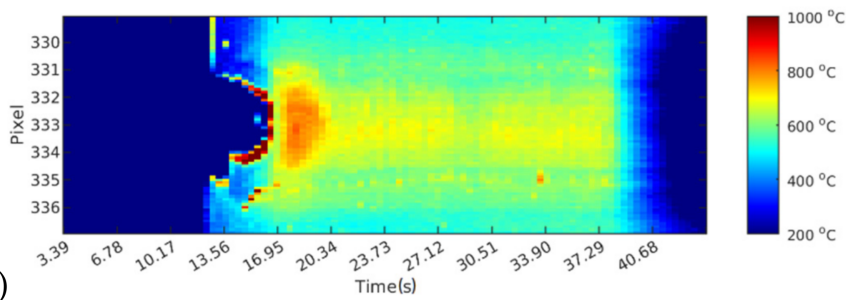

(c)

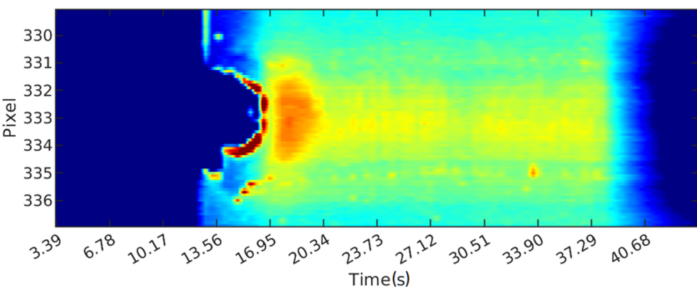

Figure 11. Results of emissivity and reflected temperature correction: (a) constant, uncorrected emissivity and reflected temperature; (b) constant corrected emissivity and uncorrected temperature; (c) constant corrected emissivity and corrected reflected temperature-correction map applied.

Temporal interpolation was performed with the method described in Section 2 and explained in Figure 4. For visualization purposes and to ease the subjective assessment of the interpolation results, a temporal reconstruction of the welds was made. It was performed by stacking consecutive bottom profiles of R1 ROI with a pixel offset that corresponded to the welding speed. Exemplary results are presented in Figure 12. The dependence between the method, interpolation factor, and reconstruction quality is easily noticeable. It can be seen that for the interpolation factor of $24(\mathrm{fs}=2.5 \mathrm{~Hz})$, the momentary anomalies that can be caused by spatters were bigger than in the case of the joint reconstructed from the original sequence. Additionally, some of the small areas of increased temperature were removed as a result of the aliasing process caused by the too-low sampling frequency that was insufficient to reconstruct the original 2D joint signal. For the highest interpolation factor $(192, \mathrm{fs}=0.3 \mathrm{~Hz})$, even the welding plate geometry was not similar to the original one and all hot spots were removed from the reconstructed welded joint IR image.

Calibrated IR sequences were decimated to generate low fps datasets. The decimation steps were selected to generate sequences which, after interpolation with factors 2, 4, 12, $24,48,96$, and 192, provided the resulting sequences with a framerate of $60 \mathrm{fps}$ (acquisition frequency $60 \mathrm{~Hz}$ ). (a)

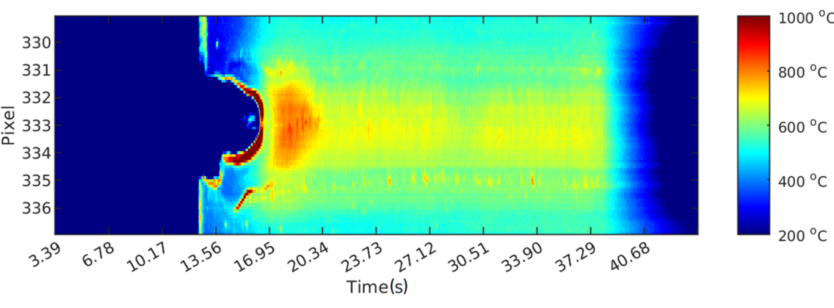

(c)
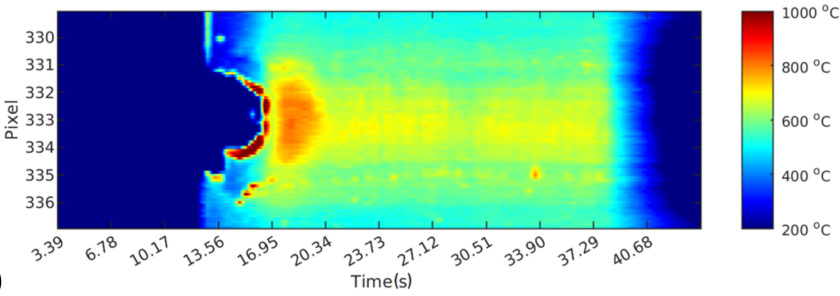

(b)
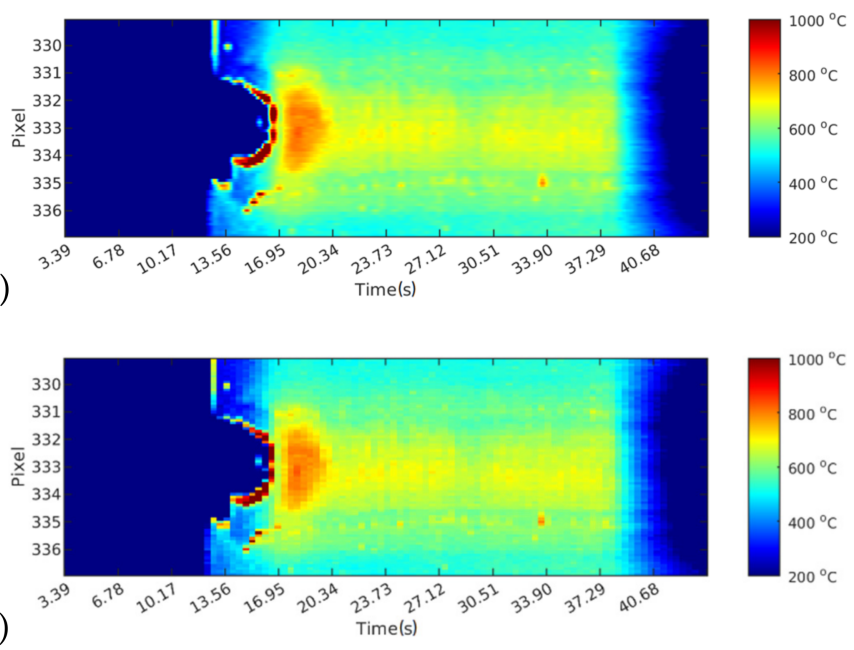

Figure 12. Cont. 
(e)

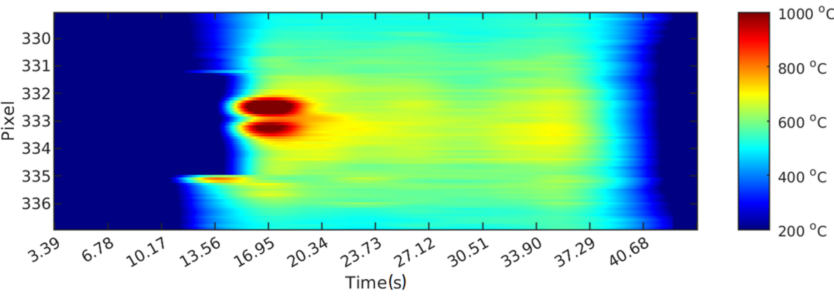

(f)

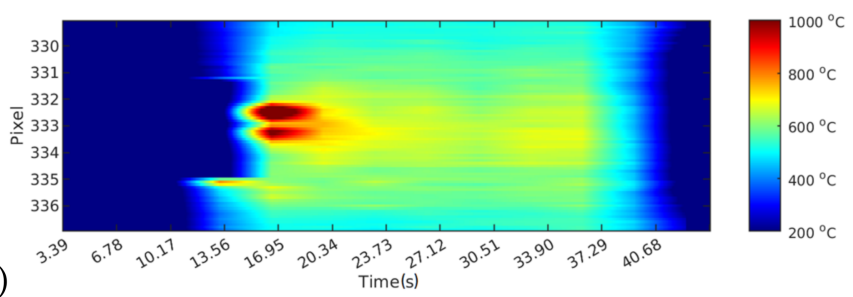

(g)

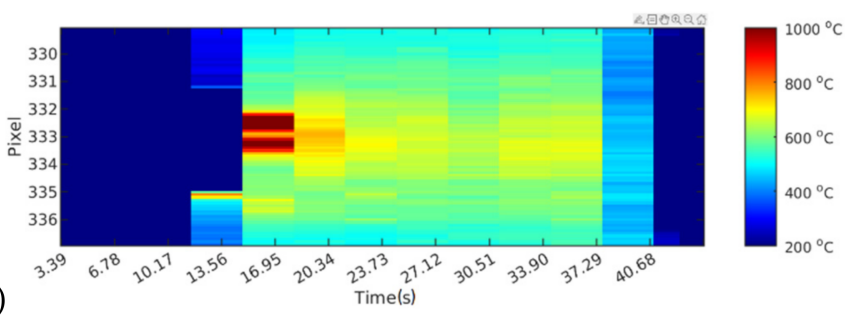

Figure 12. Temporal joint reconstruction for R1 bottom edge profile of S13: (a) original IR sequence and interpolated sequences; (b) cubic interpolation, 24; (c) linear interpolation, 24; (d) nearest neighbor interpolation, 24; (e) cubic interpolation, 192; (f) linear interpolation, 192; and (g) nearest neighbor interpolation, 192.

To quantify the similarity between the original sequence and interpolated ones, the error, which is the mean difference between the whole sequences, was calculated. Additionally, the maximal difference in a single thermogram pair was found. Results are presented in Table 4 and visualized in Figure 13. For the interpolation factor of 2, the mean difference was $\sim 18^{\circ} \mathrm{C}$ for $\mathrm{L}$ and $\mathrm{C}$ methods, while for $\mathrm{N}$, it was more than $47^{\circ} \mathrm{C}$. For interpolation factors higher than 4 , the error grew rapidly. This was the case especially for the N method because its error was more than 50\% higher than for other methods. For the highest interpolation factor, the mean error exceeded $400{ }^{\circ} \mathrm{C}$, while at the same time, the maximal error was higher than $800^{\circ} \mathrm{C}$.

Table 4. Mean interpolation error between the original and interpolated IR sequences for all the considered interpolation methods and factors.

\begin{tabular}{cccc}
\hline Interpolation Factor & Nearest (N) & Linear (L) & Cubic (C) \\
\hline 2 & 47.4 & 18.18 & 17.49 \\
4 & 62.38 & 32.69 & 32.79 \\
4 & 150.79 & 63.79 & 53.38 \\
5 & 246.34 & 122.7 & 116.47 \\
42 & 347.52 & 208.61 & 209.89 \\
98 & 403.36 & 286.38 & 287.96 \\
196 & 449.52 & 371.03 & 378.31 \\
\hline
\end{tabular}

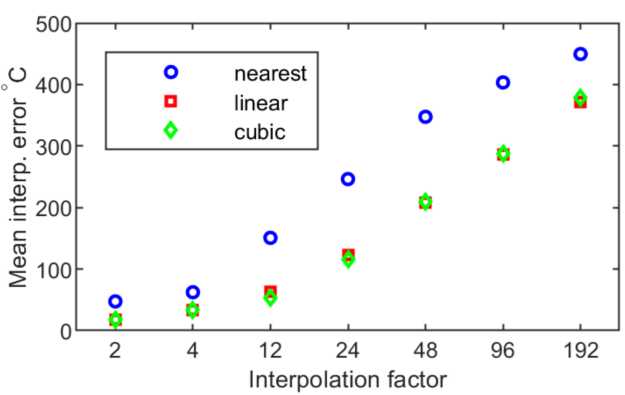

(a)

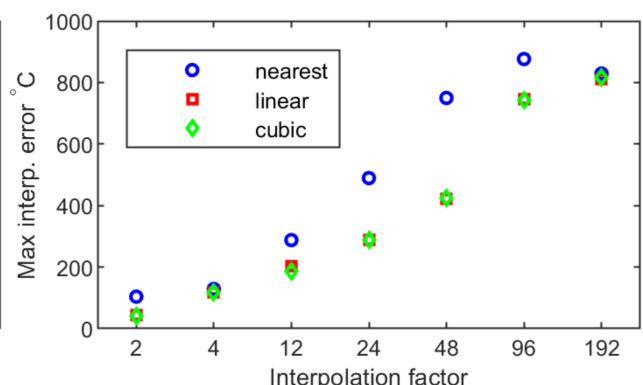

(b)

Figure 13. Comparison of similarity between the original IR sequence and the interpolate sequences: (a) mean error and (b) maximal error. 
In analyzing the results presented in Figure 14, we noticed a relationship between the temperature and voltage when increasing the interpolation factor. The objective measures support the conclusion that arises from the subjective evaluation of the reconstructed joints, as depicted in Figure 12. Dynamics of fast voltage changes are limited by the increasing gap between consecutive thermograms and according to the obtained results, it can be stated that the acquisition frequency of $2.5 \mathrm{~Hz}$ is the lowest for which the process behavior was present in the IR sequence. However, it should be emphasized that there were no small defects introduced that would be omitted in the case of the long sampling step.
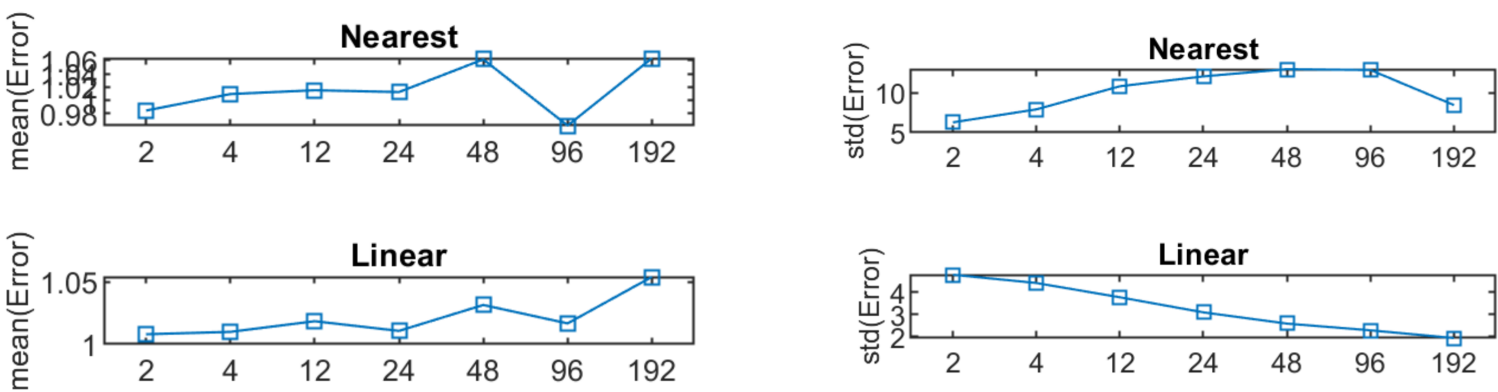

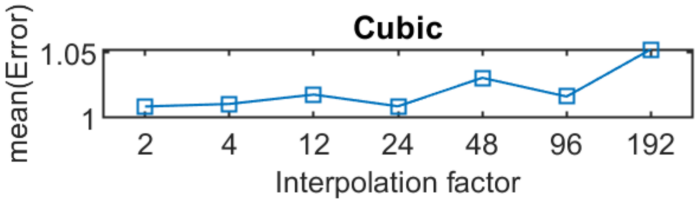

(a)

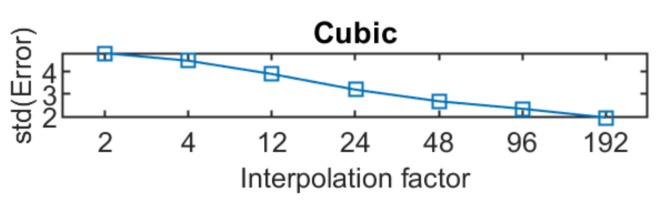

(b)

Figure 14. Mean error (a) and error standard deviation (b) describing the difference between the normalized temperature in $\mathrm{R} 1$ and the arc voltage.

The error metrics defined above are suitable to quantify the dynamic of difference of the changes between the surface temperature and voltage. To additionally check the relationship of these two parameters, the cross-correlation was used. A xcorr measure was introduced and calculated as follows:

$$
\operatorname{xcorr}\left(\boldsymbol{T}_{i, j, f}^{k, n}{ }_{f}^{d} \boldsymbol{U}_{y u, i}\right)=\text { mean }\left|R_{X Y}\left(\boldsymbol{T}_{i, j}^{k, n},{ }_{f}^{d} \boldsymbol{U}_{y u, i}\right)\right|
$$

where $R_{X Y}$ is a windowed cross-correlation function used to calculate the correlation coefficient in a window of 25 samples. The absolute value of $R_{X Y}$ is then smoothed using the moving average function.

The standard deviation of the $x$ corr feature for the nearest neighbor interpolation decreased for the highest interpolation factors because the mean xcorr was so low, near to zero, and also the maximal $x$ corr for those cases was close to the mean, as depicted in Figure 15. For other methods, it is noticeable that xcorr decreased with the increase of the interpolation factor but the spread between the minimal and maximal xcorr was higher than it was for the nearest neighbor.

Detection was made according to threshold rules constructed on the basis of two diagnostic signals that are defined as follows:

$$
\begin{aligned}
& \boldsymbol{T}_{b d i f f}^{i n}=\boldsymbol{T}_{100 \%}^{i n}-\boldsymbol{T}_{20 \%}^{i n} \\
& \boldsymbol{T}_{b \text { diff }}^{o}=\boldsymbol{T}_{100 \%}^{o}-\boldsymbol{T}_{20 \%}^{o}
\end{aligned}
$$

The common statistics above were both calculated in terms of the mean, median, standard deviation, and variance. Results are gathered in Table 5. Reference values reflect the change of temperature on the surface that is visible on the original, but not the interpolated, thermograms. We found that the most significant change was observed in 
the variance. For the sample S23, only the part with the burnout was estimated (S23*). All statistics were calculated using sliding windows of length equal for 50 samples.
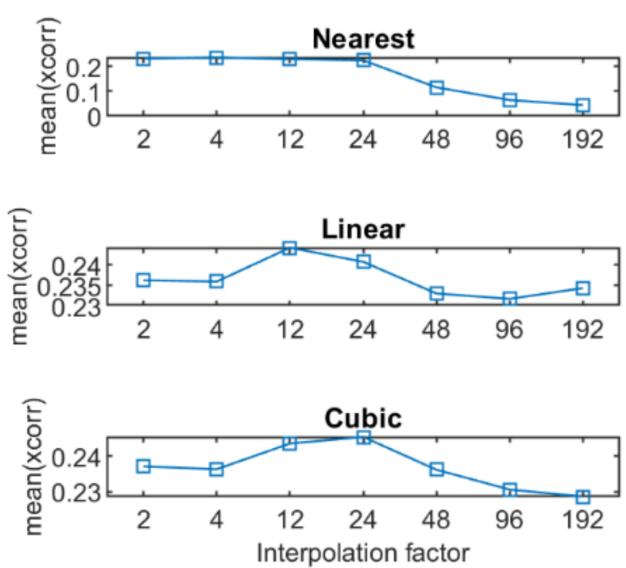

(a)
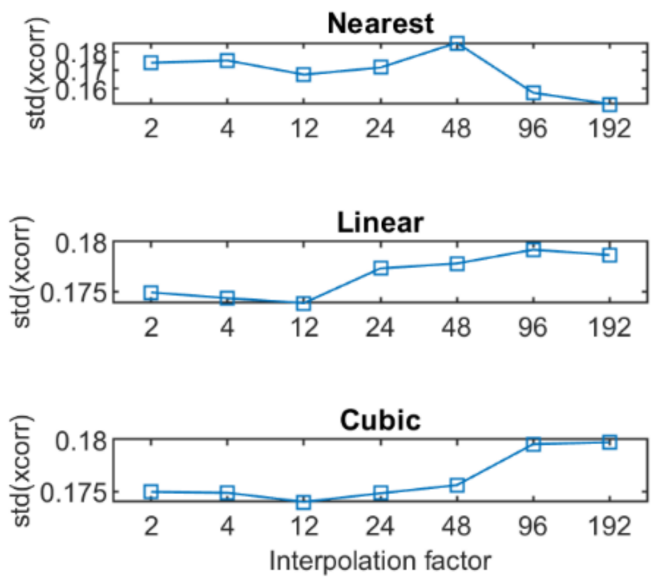

(b)

Figure 15. Mean xcorr (a) and xcorr standard deviation (b) describing the difference between the normalized temperature in R1 and the arc voltage.

Table 5. Temperature statistics in inner $\boldsymbol{T}_{b d i f f}^{\text {in }}$ and outer $\boldsymbol{T}_{b d i f f}^{o}$ joint bands.

\begin{tabular}{|c|c|c|c|c|c|c|c|c|}
\hline \multirow{2}{*}{ ID } & \multicolumn{4}{|c|}{$T_{b d i f f}^{o}$} & \multicolumn{4}{|c|}{$T_{\text {bdiff }}^{\text {in }}$} \\
\hline & Mean & Median & Std. Dev & Variance & Mean & Median & Std. Dev & Variance \\
\hline S13 & 39.93 & 39.78 & 4.08 & 16.66 & TM35.44 & Tм35.65 & 6.52 & 42.56 \\
\hline S14 & 44.35 & 44.44 & 2.99 & 8.96 & тм2.76 & тм1.92 & 5.83 & 33.96 \\
\hline S15 & 78.31 & 77.72 & 4.60 & 21.19 & тм1.61 & Tм2.58 & 8.18 & 66.85 \\
\hline S16 & 73.13 & 73.39 & 3.46 & 11.97 & 8.24 & 8.03 & 5.05 & 25.53 \\
\hline S17 & 81.36 & 81.36 & 3.33 & 11.10 & тм2.05 & 3.04 & 17.49 & 305.98 \\
\hline S18 & 90.46 & 90.49 & 5.85 & 34.21 & тм11.27 & тм 6.65 & 17.21 & 296.32 \\
\hline S19 & 88.42 & 88.42 & 3.38 & 11.43 & тм 46.75 & тм45.92 & 15.21 & 231.47 \\
\hline $\mathrm{S} 20$ & 86.31 & 86.31 & 4.56 & 20.79 & тм 49.42 & тм 49.62 & 13.95 & 194.48 \\
\hline $\mathrm{S} 22$ & 84.21 & 84.21 & 3.88 & 15.03 & тм49.42 & тм148.26 & 47.05 & 2213.41 \\
\hline S23* & 115.48 & 117.36 & 13.04 & 170.15 & тм158.97 & тм 480.55 & 120.34 & $14,482.91$ \\
\hline $\mathrm{S} 24$ & 63.53 & 61.75 & 8.92 & 79.52 & тм 470.30 & тм29.78 & 76.11 & 5792.80 \\
\hline
\end{tabular}

Considering the obtained statistics, the variance of band signals $v T_{b d i f f}^{i n}$ and $v T_{b d i f f}^{o}$ was used to determine the actual conditions of the decision thresholds that were selected. It can be used to divide

$$
\begin{gathered}
f_{i d x}\{o k\}=\left\{\begin{array}{c}
1 \text { if } \boldsymbol{v} \boldsymbol{T}_{b d i f f}^{i n} \leq 100 \text { and } \boldsymbol{v} \boldsymbol{T}_{b d i f f}^{o} \leq 50 \\
0 \text { otherwise }
\end{array}\right. \\
f_{i d x}\left\{n o k_{B}\right\}=\left\{\begin{array}{c}
1 \text { if } \boldsymbol{v} \boldsymbol{T}_{b d i f f}^{i n}>2500 \text { and } \boldsymbol{v} \boldsymbol{T}_{b d i f f}^{o}>50 \\
0 \text { otherwise }
\end{array}\right. \\
f_{i d x}\left\{n o k_{I P}\right\}=\left\{\begin{array}{c}
1 \text { if } \boldsymbol{v} \boldsymbol{T}_{b d i f f}^{\text {in }} \in\left(100 ; 2500 \text { and } \boldsymbol{v} \boldsymbol{T}_{b d i f f}^{o} \leq 50\right. \\
0 \text { otherwise }
\end{array}\right.
\end{gathered}
$$

If all quality indicators are equal to 0 , there is an unknown type of fault detected, specifically $f_{i d x}\left\{n o k_{U K N}\right\}$ :

$$
f_{i d x}\left\{n o k_{U K N}\right\}=\left\{\begin{array}{c}
1 \text { if } f_{i d x}\{o k\}=0 \text { and } f_{i d x}\left\{n o k_{I P}\right\}=0 \text { and } f_{i d x}\left\{n o k_{B}\right\}=0 \\
0 \text { otherwise }
\end{array}\right.
$$


In Figures 16-18, there is a comparison between the results obtained for the original IR image sequence that was taken with $\mathrm{fs}=60 \mathrm{~Hz}$, as depicted in Figure 16, and the interpolated sequences when thermograms were acquired with $\mathrm{fs}=30 \mathrm{~Hz}$, as depicted in Figure 17; additionally, $\mathrm{fs}=0.3 \mathrm{~Hz}$ and then it was interpolated using the cubic interpolation method to $60 \mathrm{~Hz}$. There was only slight difference between the sequences sampled with $\mathrm{fs}=60 \mathrm{~Hz}$ and $\mathrm{fs}=30 \mathrm{~Hz}$. When there were no point defects, the detection quality was on a high level. The case of $\mathrm{fs}=0.3 \mathrm{~Hz}$ is a completely different situation. Small variations of diagnostic signals $\boldsymbol{T}_{b}^{m}$ and $\boldsymbol{T}_{b}^{o}$ vanished. It can be seen that the resulting instabilities at the beginning of the welding, resulting in the small burn-through, were undetected. Differences between the cubic interpolation and the nearest neighbor method can be analyzed by comparing the results of Figures 18 and 19. Replication of known values in the nearest neighbor method leads to a diagnostic signal containing a set of sections with the same value.

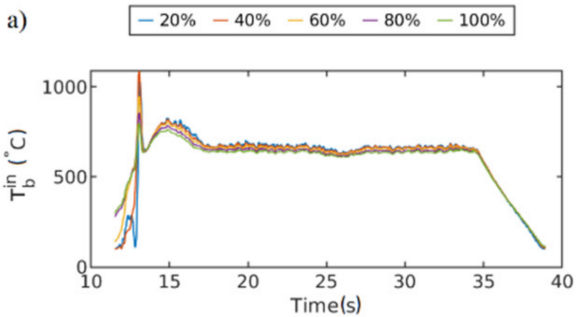

c)

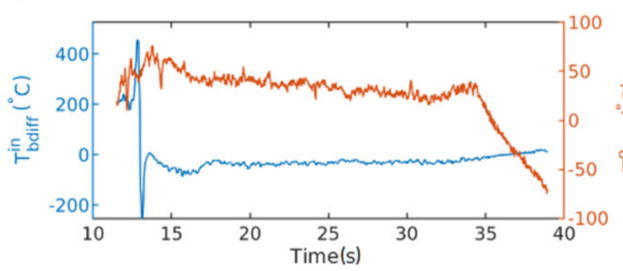

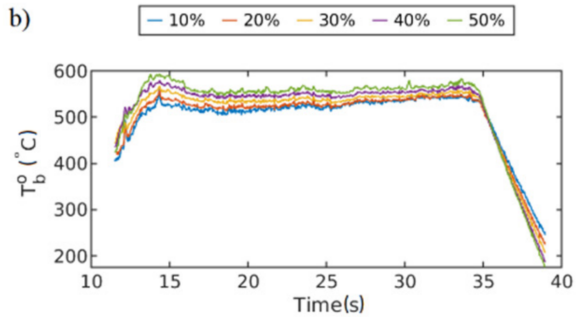

d)

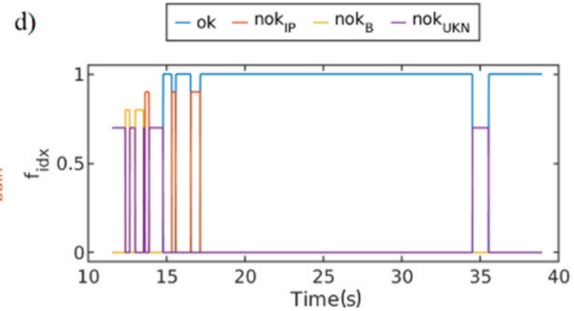

Figure 16. Feature and detection result for S13 using the original IR sequence: (a) inner band temperature distribution $\boldsymbol{T}_{b}^{i n}$, (b) outer band temperature distribution $\boldsymbol{T}_{b}^{i n}$, (c) diagnostic signals $\boldsymbol{T}_{b d i f f}^{\text {in }}$ and $\boldsymbol{T}_{b d i f f}^{o},(\mathbf{d})$ weld defect detection result.

a)

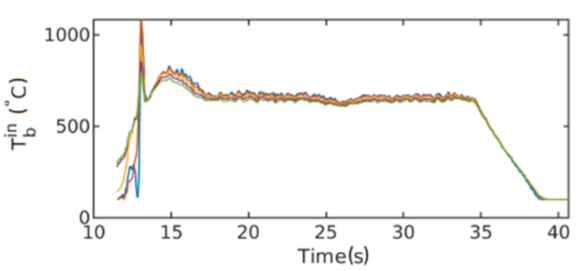

c)

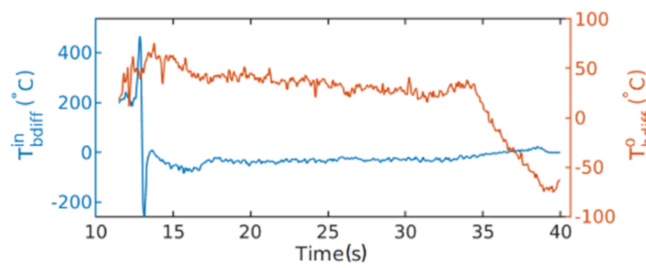

b) $-10 \%-20 \%-30 \%-40 \%-50 \%$

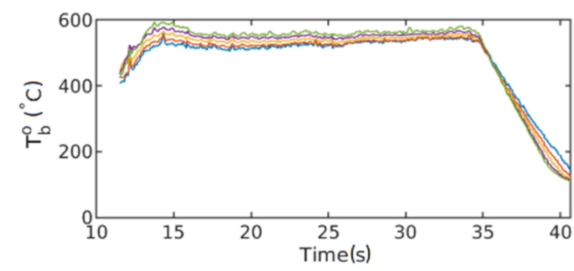

d)

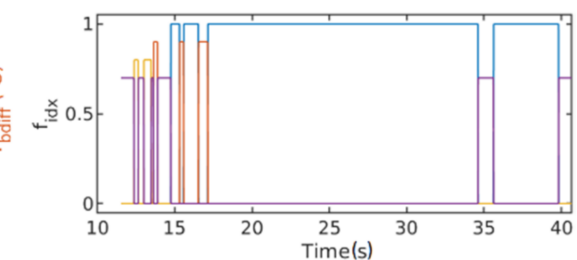

Figure 17. Feature and detection result for S13 using the interpolated IR sequence obtained using cubic interpolation with the interpolation factor $=2$ : (a) inner band temperature distribution $\boldsymbol{T}_{b}^{\text {in }},(\mathbf{b})$ outer band temperature distribution $\boldsymbol{T}_{b}^{i n}$, (c) diagnostic signals $\boldsymbol{T}_{b d i f f}^{\text {in }}$ and $\boldsymbol{T}_{b d i f f}^{o}{ }^{\prime}(\mathbf{d})$ weld defect detection result. 


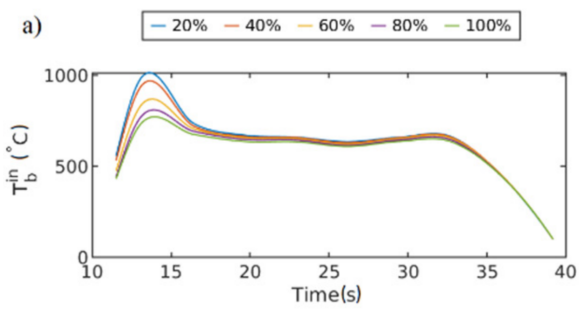

c)

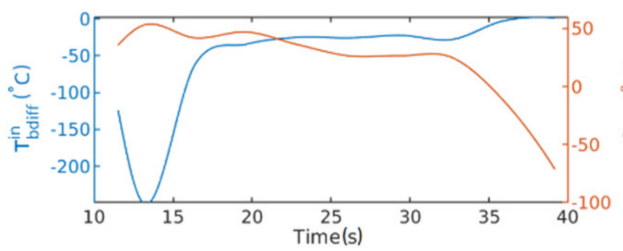

b)

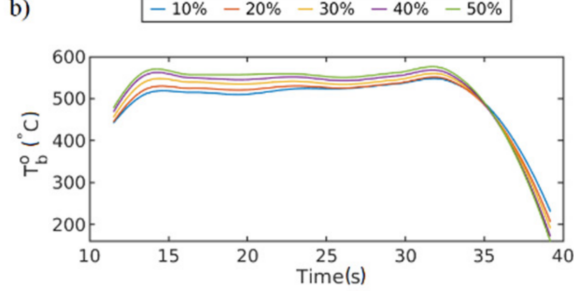

d)

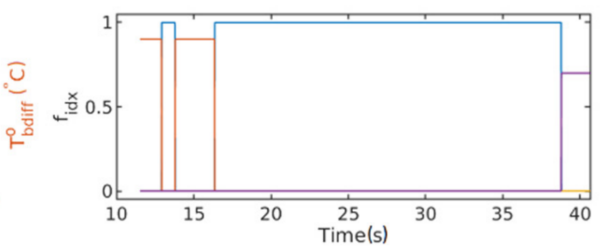

Figure 18. Feature and detection result for S13 using the interpolated IR sequence obtained using cubic interpolation with the interpolation factor = 196: (a) inner band temperature distribution $\boldsymbol{T}_{b}^{i n}$, (b) outer band temperature distribution $T_{b}^{i n}$, (c) diagnostic signals $T_{b d i f f}^{\text {in }}$ and $T_{b d i f f}^{o},(\mathbf{d})$ weld defect detection result.

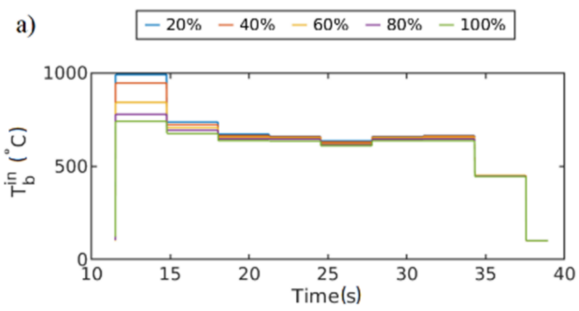

c)

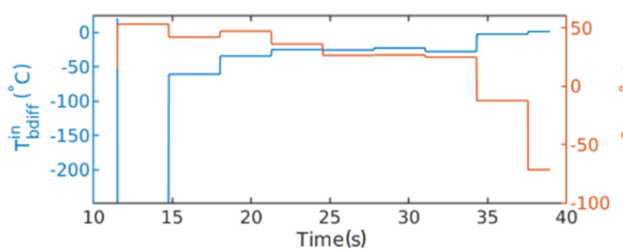

b)

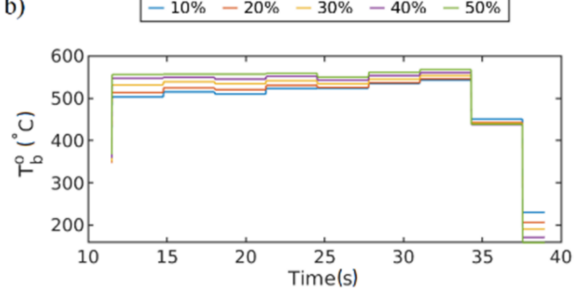

d)

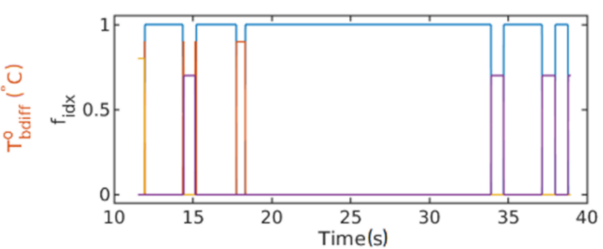

Figure 19. Feature and detection result for S13 using the interpolated IR sequence obtained using nearest neighbor interpolation with the interpolation factor $=196$ : (a) inner band temperature distribution $T_{b}^{i n}$, (b) outer band temperature distribution $T_{b}^{i n}$, (c) diagnostic signals $T_{b d i f f}^{\text {in }}$ and $T_{b d i f f}^{o}$, (d) weld defect detection result.

The influence of the sampling rate on the results for case S19 is visible in the results of detection, presented in Figures 20 and 21. In decreasing the acquisition frequency, results tend to the correct joint detection, which is a false positive decision.

The assessment of the method accuracy was made by absolute and relative measures. The first method was based on applying the absolute evaluation method based on X-ray examination results and ground-truth detection plots were manually created. All plots cover corrected joint localizations as well as penetration/fusion defects and burn-throughs. The relative method was based on a comparison between the detection results obtained for the original IR sequence and the interpolated sequences (Figure 22). Thus, better results emphasize that the interpolated sequence was more similar to the original one, while the detection method quality was assessed indirectly. 

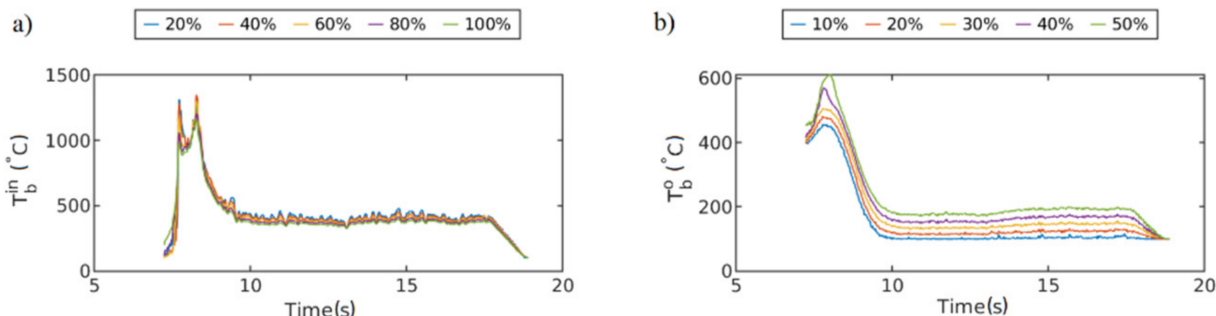

c)

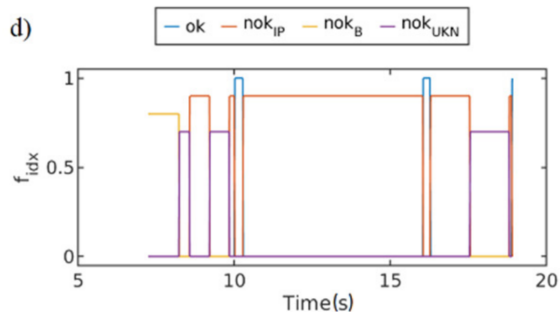

Figure 20. Feature and detection result for S19 using the original IR sequence: (a) inner band temperature distribution $\boldsymbol{T}_{b}^{i n}$, (b) outer band temperature distribution $\boldsymbol{T}_{b}^{i n}$, (c) diagnostic signals $\boldsymbol{T}_{b d i f f}^{i n}$ and $T_{b d i f f}^{o},(d)$ weld defect detection result.
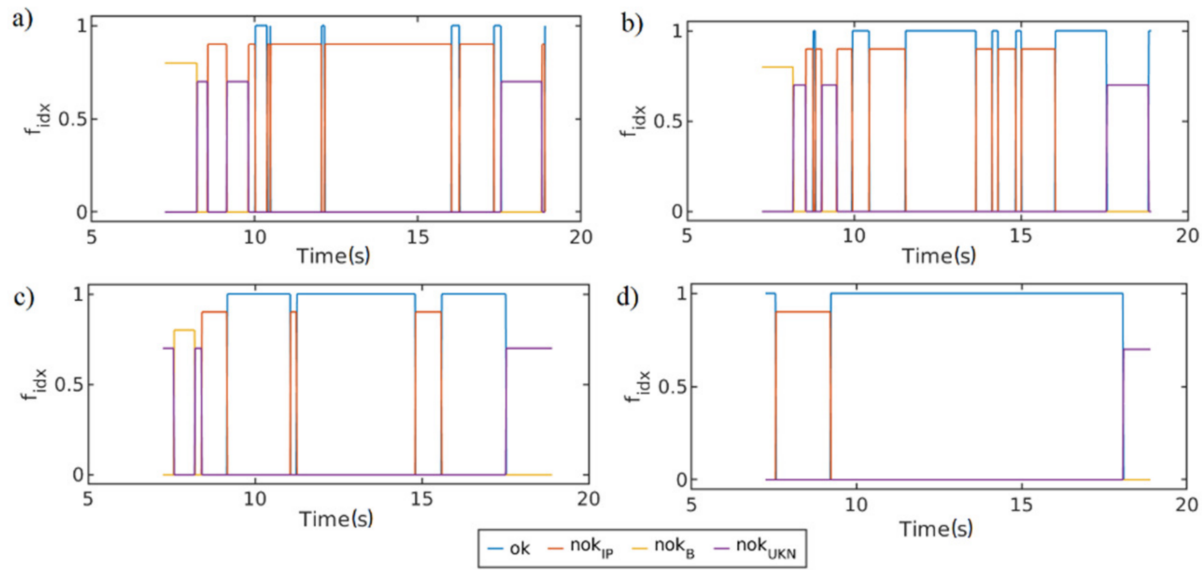

Figure 21. Comparison of detection results using cubic interpolation for sample S19 with different interpolation factors: (a) 2, (b) 24, (c) 48, and (d) 192.

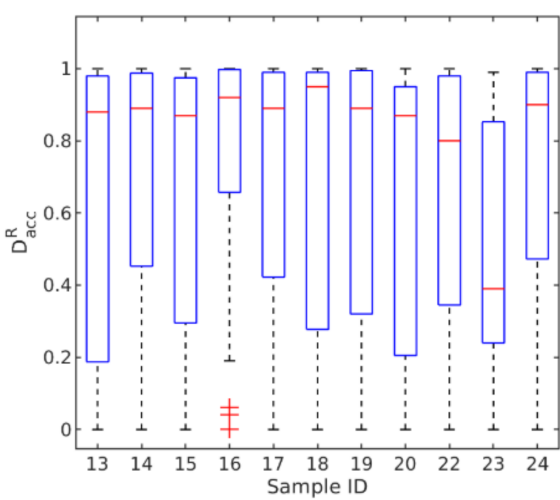

(a)

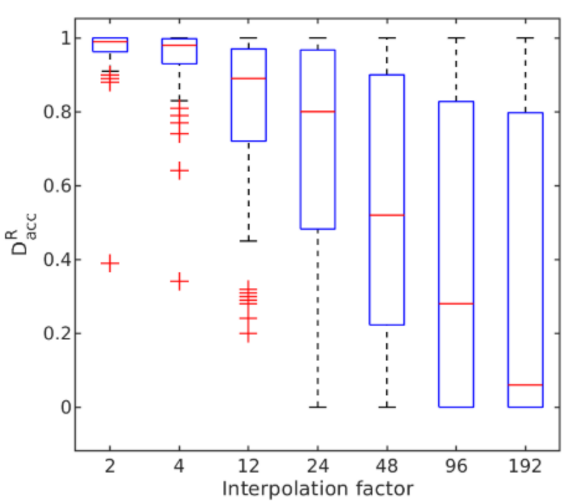

(b)

Figure 22. Relative results of overall detection accuracy for all interpolation methods and all considered joint conditions, specifically (a) for each workpiece and (b) for individual interpolation factors. 
For the absolute assessment, the results are presented in Figures 23-25. Figure 23 presents the results obtained when the detection of the correct joints was performed, Figure 24 presents the results from the of lack fusion/penetration detection, and Figure 25 presents the burn-through detection. For all cases, there are three group of results presented that differ in terms of the interpolation factor influencing the acquisition frequency of input IR images. The higher the interpolation factor, the lower the acquisition frequency. It is easy to notice that for lower acquisition rates, the median value of accuracy was lower, and there was a larger spread between the minimum and maximum accuracy, thus the detection was less stable. The detection of burn-through is the most complicated task as there was no fixed way in which the material was removed. The absolute accuracy values emphasize the fact that in steady conditions, the detection accuracy was also vulnerable to accuracy-decrease for higher interpolation factors. For the constant time windows used for the $\boldsymbol{v} \mathbf{T}_{b d i f f}^{m}$ and $\boldsymbol{v} \mathbf{T}_{b d i f f}^{o}$ calculation, the signals were smoother and momentary changes, which were the result of condition changes, were faint. It can be seen in Figure 21 for the sample S19, for which the joint was faulty (insufficient penetration), the sampling frequency lower than $\mathrm{fs}=1.25 \mathrm{~Hz}$ (interpolation factor 48) detection was incorrect for identifying the correct joint. When burn-through raised at the beginning and at the end of the sample, and the trolley stood still and the arc was still glowing, sample S23, as depicted in Figure 8d, was greatly different, as in the case of the completely separated plates regarding sample S24, depicted in Figure 9. Uneven distribution of heat at the plates edges caused by the changes in geometry makes the tuning of decision thresholds a difficult task.

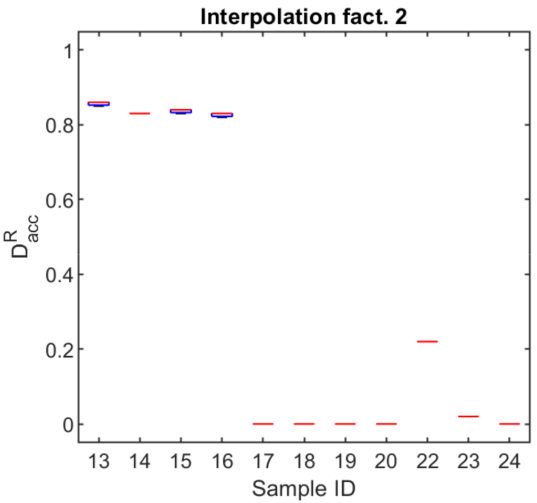

(a)

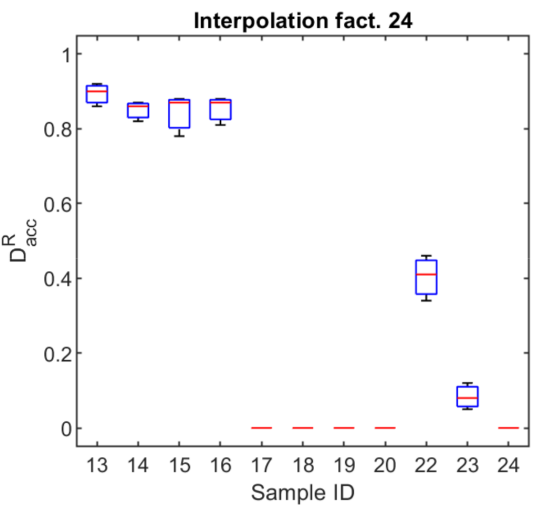

(b)

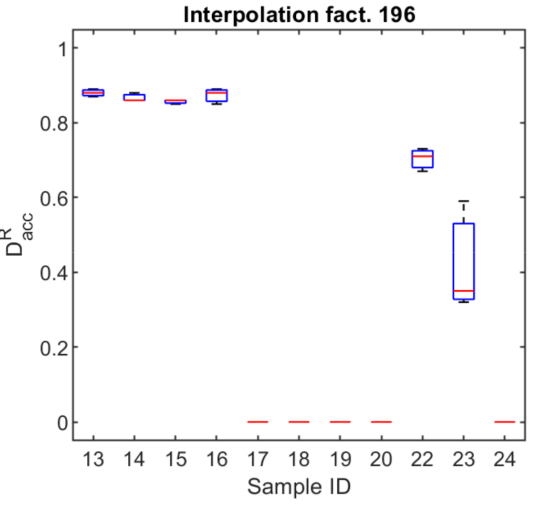

(c)

Figure 23. Absolute overall detection accuracy for the correct joint for different interpolation factors: (a) 2, (b) 24 , (c) 192.

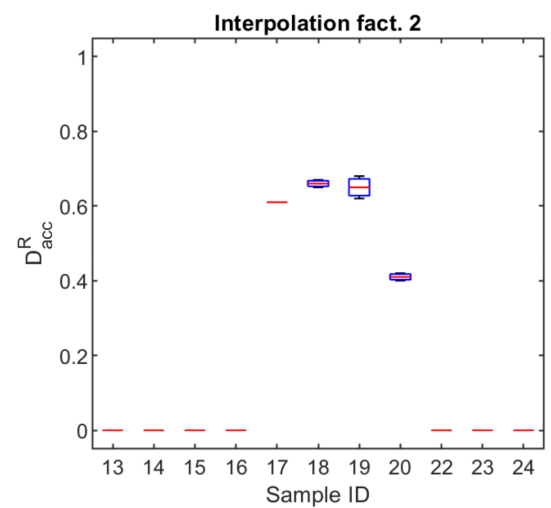

(a)

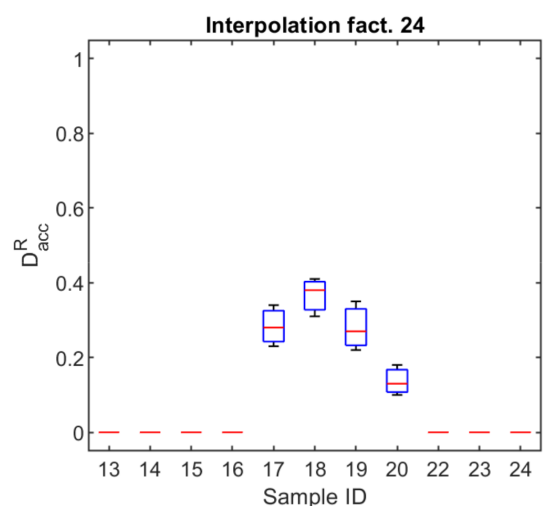

(b)

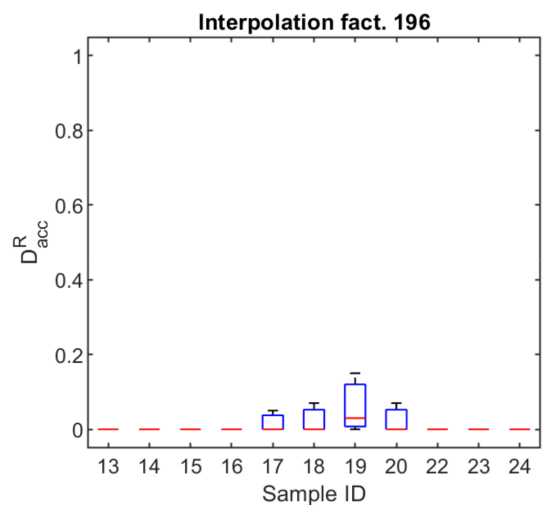

(c)

Figure 24. Absolute overall detection accuracy for the incorrect joint regarding the lack of fusion/penetration: (a) 2, (b) 24 , (c) 192. 


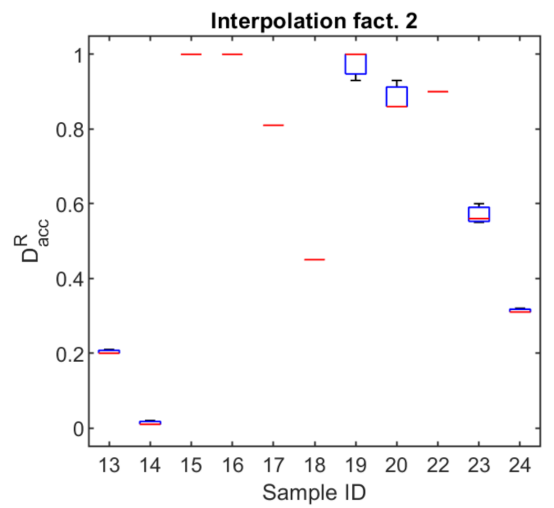

(a)

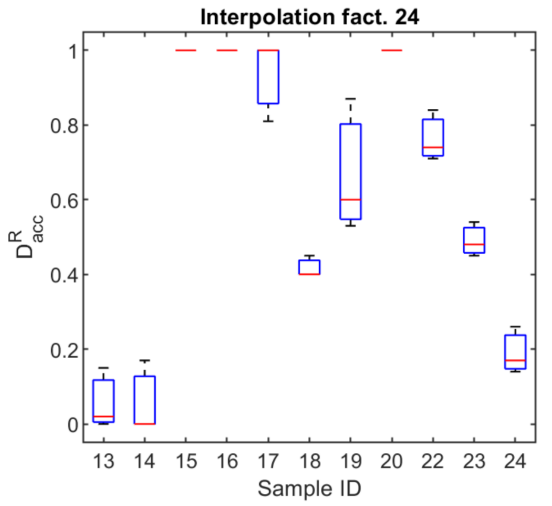

(b)

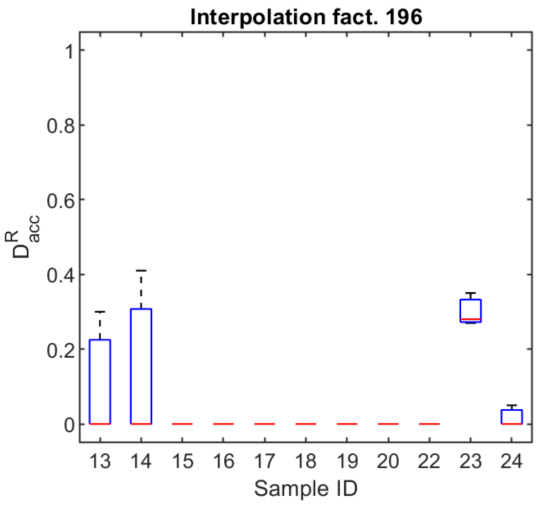

(c)

Figure 25. Absolute overall detection accuracy for the incorrect joint regarding the burn-through defect: (a) 2, (b) 24 , (c) 192.

\section{Conclusions}

Applying thermovision to check the quality of welds in an on-line/in-line mode is a common approach. In the literature, thermovision is mostly presented as a tool suitable for monitoring and diagnosing laser welding [28-30]. In this process, there is a relatively low influence of heat generated by the welding equipment on the temperature distribution, on a large surface of the welded workpiece. Moreover, in this case, the IR camera can be applied to observe the welding pool because it is not covered by the large welding torch. In other methods, especially in arc welding, such as in TIG, MIG, and MAG, the welding pool and, even more often, a joint in the cooling phase are observed. Unfortunately, when working with metallic surfaces of low emissivity, the real temperature distribution demanded is obscured by the high heat amount emitted by the torch and the welding arc that is reflected by the surface of the welded part. Applying emissivity correction is crucial and is often conducted in practice by taking values from literature or making experimental estimations of this parameter. Reflected temperature correction is not common and when applied, a constant temperature is taken. Using the map for reflected temperature correction, the temperature pattern generated by the hot welding torch and the welding arc is removed. This allows for the increase of the real temperature uniformity and confidence of the taken thermograms. However, this approach also has several limitations that are the result of small numbers of thermocouples offering the reference temperature. Moreover, it is difficult to evaluate and measure the quality of correct ions because there is no known exact temperature distribution on the workpiece surface.

The most difficult factor to identify and the most vulnerable to acquisition frequencydecrease was the burn-through. This was because the changing heat occurring when the input sequence was acquired with frequencies lower than $1 \mathrm{~Hz}$ made it impossible to detect this type of defect. For other conditions (ok/nok), lowering the acquisition rate below $1 \mathrm{~Hz}$ lead to a rapid decrease of the detection quality. The longest sampling interval of $3.2 \mathrm{~s}(0.31 \mathrm{~Hz})$ led to a situation in which a large defect could remain undetected. For the welding speed $3 \mathrm{~mm} / \mathrm{s}$, the IR image rolled with $\sim 17 \mathrm{px} / \mathrm{s}$; thus, for used hardware configurations, where $1 \mathrm{px} \approx 0.15 \mathrm{~mm}$ for the time offset of $3 \mathrm{~s}$, the thermovision system is omits $7.65 \mathrm{~mm}$ of the joint. The worst case occurred when the welding speed was increased. For $7 \mathrm{~mm} / \mathrm{s}$, there was $\sim 38 \mathrm{px} / \mathrm{s}$ and the unseen part of the weld was $17.1 \mathrm{~mm}$ long.

For all methods, including the cubic interpolation, the difference between feature values and diagnostic signals was too low to distinguish between correct and incorrect joints. It can be seen that if the process is stable, producing correct joints, and if it constantly produces incorrect joints (e.g., wrong parameters leading to a lack of fusion on the whole joint length), the influence of the lower acquisition frequency is small. Nevertheless, welding is a dynamic process and, most often, momentary disturbances affect the overall joint quality, thus it must be stated that having higher acquisition speeds available can result in a better detectability of small size defects such as inclusions and pores. Temporal 
interpolation can be applied successfully to increase the detection accuracy for selected weld defects. Nevertheless, it is necessary to be aware of the minimal sampling accuracy that is needed to cover an adequate length of a joint.

Future research will include an elaboration of the thermogram rectification method and will explore the potential improvement occurring if reflected temperature correction mapping is employed using results from numerical simulations of welding. Additionally, a better detection algorithm incorporating machine learning techniques for joint quality and process stability assessment will be explored.

Author Contributions: Conceptualization, W.J. and J.G.; methodology, W.J. and J.G.; software, W.J.; validation, W.J. and J.G.; formal analysis, W.J.; investigation, W.J. and J.G.; resources, W.J.; data curation, W.J.; writing-original draft preparation, W.J.; writing-review and editing J.G.; visualization, W.J.; project administration, W.J.; funding acquisition, W.J. All authors have read and agreed to the published version of the manuscript.

Funding: This research study was funded by the National Science Centre (NCN), Miniatura 3 project, grant number 2019/03/X/ST8/00422.

Institutional Review Board Statement: Not applicable.

Informed Consent Statement: Not applicable.

Data Availability Statement: The data presented in this study are available upon request from the corresponding author. The data are not publicly available because the authors do not wish to publish supplementary materials.

Conflicts of Interest: The authors declare no conflict of interest. The funders had no role in the design of the study; in the collection, analyses, or interpretation of data; in the writing of the manuscript, or in the decision to publish the results.

\section{References}

1. Kik, T. Heat Source Models in Numerical Simulations of Laser Welding. Materials 2020, 13, 2653. [CrossRef]

2. Rogalski, G.; Świerczyńska, A.; Landowski, M.; Fydrych, D. Mechanical and Microstructural Characterization of TIG Welded Dissimilar Joints between 304L Austenitic Stainless Steel and Incoloy 800HT Nickel Alloy. Metals 2020, 10, 559. [CrossRef]

3. Ghetiya, N.; Pandya, D. Mathematical Modeling for the Bead Width and Penetration in Activated TIG Welding Process. In Proceedings of the International Conference on Multidisciplinary Research \& Practice, Gujarat, India, 30 November 2014; Volume 1, pp. 247-252.

4. Tomków, J.; Sobota, K.; Krajewski, S. Influence of tack welds distribution and welding sequence on the angular distortion of tig welded joint. Facta Univ. Ser. Mech. Eng. 2020, 18, 611-621. [CrossRef]

5. Tseng, K.-H.; Hsu, C.-Y. Performance of activated TIG process in austenitic stainless steel welds. J. Mater. Process. Technol. 2011, 211, 503-512. [CrossRef]

6. Tsai, C.-H.; Hou, K.-H.; Chuang, H.-T. Fuzzy control of pulsed GTA welds by using real-time root bead image feedback. J. Mater. Process. Technol. 2006, 176, 158-167. [CrossRef]

7. Skowrońska, B.; Chmielewski, T.; Kulczyk, M.; Skiba, J.; Przybysz, S. Microstructural Investigation of a Friction-Welded 316L Stainless Steel with Ultrafine-Grained Structure Obtained by Hydrostatic Extrusion. Materials 2021, 14, 1537. [CrossRef]

8. Liu, Y.; Zhang, Y. Weld penetration control in gas tungsten arc welding (GTAW) process. In Proceedings of the IECON 2013-39th Annual Conference of the IEEE Industrial Electronics Society, Vienna, Austria, 10-13 November 2013; IEEE: Piscataway, NJ, USA, 2013; pp. 3842-3847.

9. Jamrozik, W.; Górka, J.; Kik, T. Temperature-Based Prediction of Joint Hardness in TIG Welding of Inconel 600, 625 and 718 Nickel Superalloys. Materials 2021, 14, 442. [CrossRef] [PubMed]

10. Gucwa, M.; Winczek, J.; Giza, K.; Wieczorek, P.; Makles, K. The Effect of Welding Methods on the Corrosion Resistance of 304 Stainless Steel Joints. Acta Phys. Pol. A 2019, 135, 232-235. [CrossRef]

11. Stavridis, J.; Papacharalampopoulos, A.; Stavropoulos, P. Quality assessment in laser welding: A critical review. Int. J. Adv. Manuf. Technol. 2017, 94, 1825-1847. [CrossRef]

12. Maeda, K.; Suzuki, R.; Suga, T.; Kawahito, Y. Investigating delayed cracking behaviour in laser welds of high strength steel sheets using an X-ray transmission in-situ observation system. Sci. Technol. Weld. Join. 2020, 25, 377-382. [CrossRef]

13. Yu, W.X.; Liu, B.X.; Chen, C.X.; Liu, M.Y.; Zhang, X.; Fang, W.; Ji, P.G.; He, J.N.; Yin, F.X. Microstructure and mechanical properties of stainless steel clad plate welding joints by different welding processes. Sci. Technol. Weld. Join. 2020, 25, 571-580. [CrossRef]

14. You, D.; Gao, X.; Katayama, S. Review of laser welding monitoring. Sci. Technol. Weld. Join. 2014, 19, 181-201. [CrossRef]

15. You, D.; Gao, X.; Katayama, S. Multisensor fusion system for monitoring high-power disk laser welding using support vector machine. IEEE Trans. Ind. Inform. 2014, 10, 1285-1295. 
16. Webster, P.J.L.; Wright, L.G.; Ji, Y.; Galbraith, C.M.; Kinross, A.W.; Van Vlack, C.; Fraser, J.M. Automatic laser welding and milling with in situ inline coherent imaging. Opt. Lett. 2014, 39, 6217-6220. [CrossRef]

17. Kong, F.; Kovacevic, R. 3D finite element modeling of the thermally induced residual stress in the hybrid laser/arc welding of lap joint. J. Mater. Process. Technol. 2010, 210, 941-950. [CrossRef]

18. Snedeker, D.A. Study on Development of Techniques for RESISTANCE Welding, Phases I and II; FINAL report; Martin Marietta Corp: Orlando, FL, USA, 1967.

19. Bobo, S. Infrared radiation as a tool in non-destructive evaluation of welding and bonding. Non-Destr. Test. 1970, 3 , 345-350. [CrossRef]

20. Naksuk, N.; Nakngoenthong, J.; Printrakoon, W.; Yuttawiriya, R. Real-Time Temperature Measurement Using Infrared Thermography Camera and Effects on Tensile Strength and Microhardness of Hot Wire Plasma Arc Welding. Metals 2020, mboxemph10, 1046. [CrossRef]

21. Thomas, K.R.; Unnikrishnakurup, S.; Nithin, P.V.; Balasubramaniam, K.; Rajagopal, P.; Prabhakar, K.V.P.; Padmanabham, G.; Riedel, F.; Puschmann, M. Online monitoring of cold metal transfer (CMT) process using infrared thermography. Quant. Infrared Thermogr. J. 2016, 14, 1-11. [CrossRef]

22. Nagarajan, S.; Banerjee, P.; Chen, W.; Chin, B. Control of the welding process using infrared sensors. IEEE Trans. Robot. Autom. 1992, 8, 86-93. [CrossRef]

23. Wilik, H.C.; Kottilingam, S.; Zee, R.H. Infrared sensing techniques for penetration depth control of the sub-merged arc welding process. J. Mater. Process. Technol. 2001, 113, 228-233.

24. Al-Habaibeh, A.; Parkin, R. An autonomous low-cost infrared system for the on-line monitoring of manufacturing processes using novelty detection. Int. J. Adv. Manuf. Technol. 2003, 22, 249-258. [CrossRef]

25. Bicknell, A.; Smith, J.S.; Lucas, J. Infrared sensor for top face monitoring of weld pools. Meas. Sci. Technol. 1994, 5, 371-378. [CrossRef]

26. Farson, D.; Richardon, R.; Li, X. Infrared measurement of base metal temperature in gas tungsten arc welding. Weld. Res. Suppl. $1998,77,396$.

27. Steffensen, J.F. Interpolation, 2nd ed.; Dover Publications: Mineola, NY, USA, 2006.

28. Umar, M.; Paulraj, S. Thermography analysis and porosity formation during laser beam welding of AA5083-H111 aluminum alloy. J. Therm. Anal. Calorim. 2020, 1-9. [CrossRef]

29. Speka, M.; Matteï, S.; Pilloz, M.; Ilie, M. The infrared thermography control of the laser welding of amorphous polymers. NDT E Int. 2008, 41, 178-183. [CrossRef]

30. Rinker, T.J.; McGovern, M.E.; Brown, T.; Wang, H. Thermographic detectability of porosity in multi-layered bare and anodized aluminum laser welds. Procedia Manuf. 2020, 48, 165-171. [CrossRef] 